\title{
Estimating the Effects of Astronaut Career Ionizing Radiation Dose Limits on Manned Interplanetary Flight Programs
}

\author{
Steven L. Koontz ${ }^{1}$, Kristina Rojdev ${ }^{2}$, Gerard D. Valle ${ }^{3}$, John J. Zipay ${ }^{4}$ \\ Engineering Directorate, NASA Johnson Space Center, Houston, Texas, 77058, USA \\ William S. Atwell ${ }^{5}$ \\ Boeing Research \& Technology, Houston, Texas, 77059
}

\begin{abstract}
Space radiation effects mitigation has been identified as one of the highest priority technology development areas for human space flight in the NASA Strategic Space Technology Investment Plan (Dec. 2012). In this paper we review the special features of space radiation that lead to severe constraints on long-term ( $>180$ days) human flight operations outside Earth's magnetosphere. We then quantify the impacts of human space radiation dose limits on spacecraft engineering design and development, flight program architecture, as well as flight program schedule and cost. A new Deep Space Habitat (DSH) concept, the hybrid inflatable habitat, is presented and shown to enable a flexible, affordable approach to long term manned interplanetary flight today.
\end{abstract}

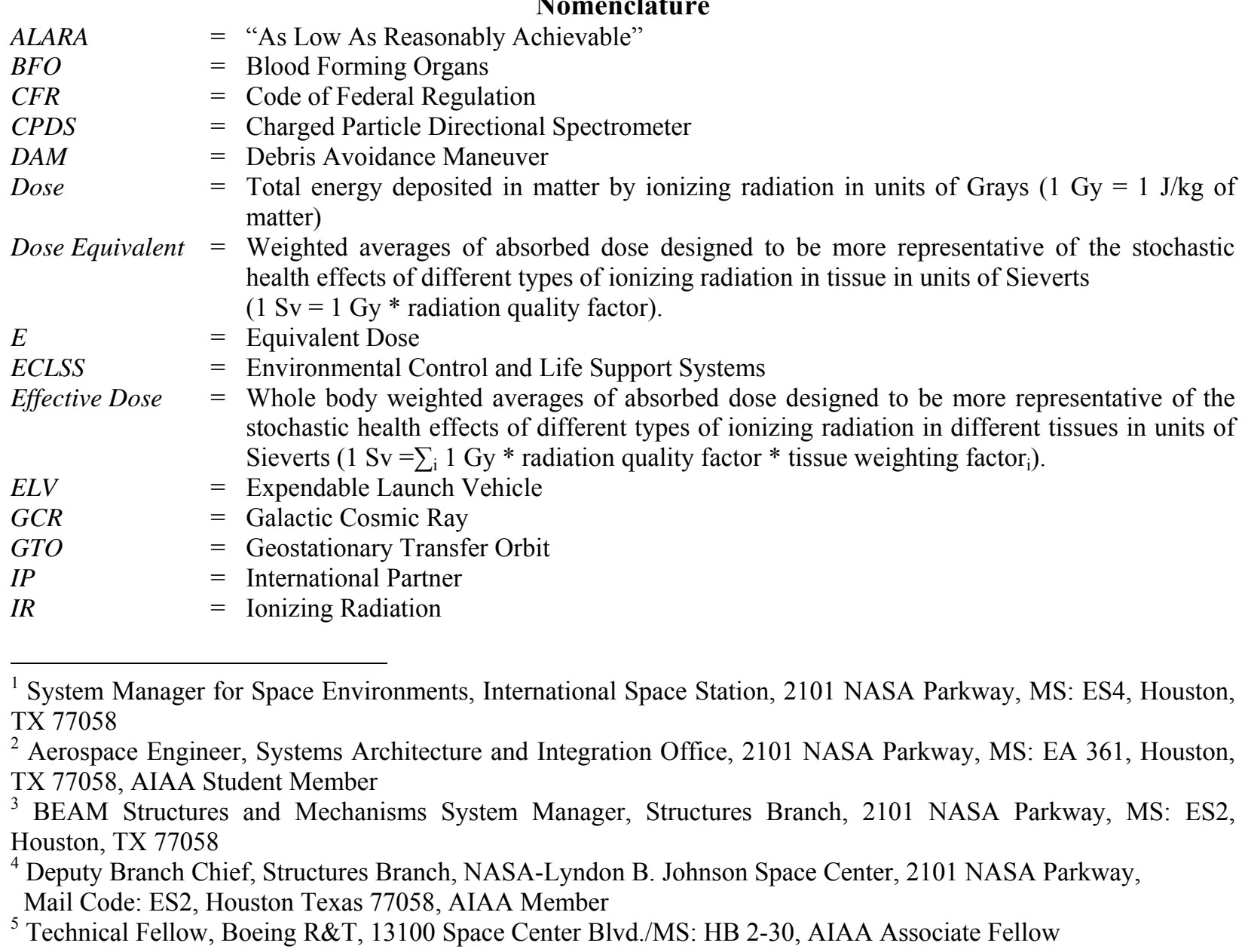

American Institute of Aeronautics and Astronautics 


$\begin{array}{ll}\text { Isp } & =\text { Specific Impulse } \\ \text { ISS } & =\text { International Space Station } \\ \text { LEO } & =\text { Low Earth Orbit } \\ M M / O D & =\text { MicroMeteoroid/ Orbital Debris } \\ \text { NASA } & =\text { National Aeronautics and Space Administration } \\ N C R P & =\text { National Council on Radiation Protection and Measurements } \\ N D S & =\text { SASA Docking System } \\ \text { OWS } & =\text { Probability of No Penetration } \\ P N P & =\text { Radiation Area Monitor } \\ \text { RAM } & =\text { Radiation Exposure Induced Death } \\ \text { REID } & =\text { Solar Particle Event } \\ \text { SPE } & =\text { Space Station Program } \\ S S P & =\text { Tissue Equivalent Proportional Counter } \\ T E P C & =\text { Van Allen Belt Dosimeter } \\ \text { TRL } & =\text { Variable Specific Impulse Magnetoplasma Rocket } \\ V A B D & \end{array}$

\section{Introduction}

In this paper we report the results of a systems engineering study aimed at quantifying the effects of changing NASA flight crew ionizing radiation dose limits on long duration manned interplanetary flight programs. We then demonstrate the benefits of a relatively mature hybrid inflatable Deep Space Habitat (DSH) technology in mitigating the negative impacts of severe human space radiation dose limits employing only technology that has a high-TRL level today.

NASA ionizing radiation career exposure limits for flight crew personnel are derived from a not-to-exceed limit of 3\% radiation-exposure-induced death (REID), from cancer, with a $95 \%$ confidence level (29 Code of Federal Regulation 1960.18), where the cancer fatality can occur many years after the space flight exposure ${ }^{1,2}$.

The slow accumulation of whole body ionizing radiation dose from galactic cosmic rays (GCR) limits the duration of manned space operations outside Earth's magnetosphere to times on the order of 180 days, assuming historically typical manned spacecraft shielding mass of 20 to $30 \mathrm{~g} / \mathrm{cm}^{2}$ aluminum and the $3 \%$ REID requirement ${ }^{3}$. Uncertainties in the dose-REID relationship for space radiation, combined with the required $95 \%$ confidence level have driven the spaceflight crew career dose limit from 100.0 E cSv to $15.0 \mathrm{E} \mathrm{cSv}$ in recent years ${ }^{4,5}$. However, ongoing work focused on both reducing the uncertainty in the dose-REID relationship and developing biomedical countermeasures promise to ultimately reduce shielding mass requirements dramatically ${ }^{4,5}$.

GCRs have substantially higher kinetic energies than solar particle event cosmic rays or geomagnetically trapped radiation so that substantially thicker, and hence heavier, shielding mass is needed to mitigate human GCR dose during long duration interplanetary space missions ${ }^{4,5}$. Collisions of GCR nuclei with stationary nuclei in the spacecraft and/or human occupants of the spacecraft can generate intense secondary particle showers that contribute a substantial percentage of the total dose $e^{4,5}$. Including the contributions to radiation dose from GCR-induced secondary particle showers in the spacecraft structure and in the human body dramatically reduces the benefits of low-atomic-number, high-hydrogen-content materials for spacecraft shielding against galactic cosmic rays that were long believed to produce adequate shielding at relatively lower total shielding mass ${ }^{4,5}$.

The overall programmatic effects (launch costs, program architecture, schedule, and ultimately dollar cost) of meeting the ionizing radiation crew dose requirements using technologically mature passive shielding materials so as to extend the 180 day limit to three years seem prohibitive at first sight. Baseline spacecraft structure and consumables cannot provide sufficient shielding mass, in themselves, as is shown in section IV below.

In the following, we first review the space radiation environment and human dose effects, as well as the various proposed approaches to mitigate those effects. Alternatives to low-atomic-number, high hydrogen-content passive shielding materials are discussed, though all the alternatives display low technological maturity and carry with them significant cost and schedule risks at this time. Some of these technologies could become available to support human interplanetary flight programs in about 10 to 15 years, but only if development is supported by continued and reliable funding.

Next we show that hybrid inflatable DSH technology offers a set of affordable solutions to the radiation dose problems accompanying long duration human space operations outside the Earth's magnetosphere, using mature technology available today while remaining flexible and adaptable enough to incorporate more advanced mitigation technologies as they becomes available without costly re-work and redesign. 
Expected future NASA budget limits and corresponding annual spending limits for manned interplanetary programs make affordability and cost control key considerations in planning future manned interplanetary space flight activities.

\section{Space Radiation Environments for Interplanetary Flights}

The space radiation environment as it affects spacecraft avionics systems and human health is dominated by energetic charged particles ${ }^{6-9}$. Energetic photons (X-rays and gamma rays) make only a very small contribution in most cases of interest ${ }^{6-9}$. The energetic charged particle environment is composed of three distinct charged particle populations, each with a different range of particle kinetic energies. In low Earth orbit (LEO), the primary contributors to the spacecraft radiation environment are geomagnetically trapped electrons and protons, and the higher energy GCRs that can penetrate the geomagnetic field. Outside Earth's magnetosphere, the spacecraft is subjected to a continuous radiation environment from galactic cosmic rays (GCRs), as well as intermittent, short lived, solar storms known as solar particle events (SPEs) ${ }^{6-9}$.

\section{A. Low Earth Orbit - Trapped particles}

In low Earth orbit (LEO), as well as in most Earth escape trajectories, the Van Allen radiation belts are an important concern. These belts are composed of both protons and electrons. The protons are higher energy and more penetrating, thus of greater concern. The radiation belts are created by particles, primarily protons and electrons, becoming trapped by the Earth's magnetic field. The number of particles within the belt changes slightly as a result of the solar cycle. Furthermore, because the magnetic axis is tilted from the Earth's rotational axis, there is a location known as the South Atlantic Anomaly where the radiation belts are much closer to the surface of the Earth. Therefore, spacecraft flying through this area tend to accumulate more radiation exposure.

In general, the LEO radiation environment is well characterized and radiation can be minimized through strategic passive shielding and materials selection ${ }^{9}$. For interplanetary missions, the importance of trapped radiation will depend on the amount of time spent in LEO, as well as the total exposure to trapped radiation during the Earth escape trajectory. Long, slow spiral escape trajectories, typical of electric propulsion, will expose the spacecraft to substantial trapped radiation doses while transiting the radiation belts. Chemical propulsion can enable rapid radiation belt transit and minimal spacecraft exposure through the most severe parts of the radiation belts 9

\section{B. Solar Particle Events}

Solar particle events (SPEs) are either solar flares or coronal mass ejections that originate from the sun and are primarily composed of protons. The sun follows an approximately 11 year cycle where it goes through periods of intense activity, followed by periods of decreased activity (Fig. 1) ${ }^{9}$. These periods are known as solar maximum and solar minimum, respectively. The cycle of the sun is characterized by the number of sunspots visible. Solar particle events originate in these sun spots ${ }^{9,10}$. 

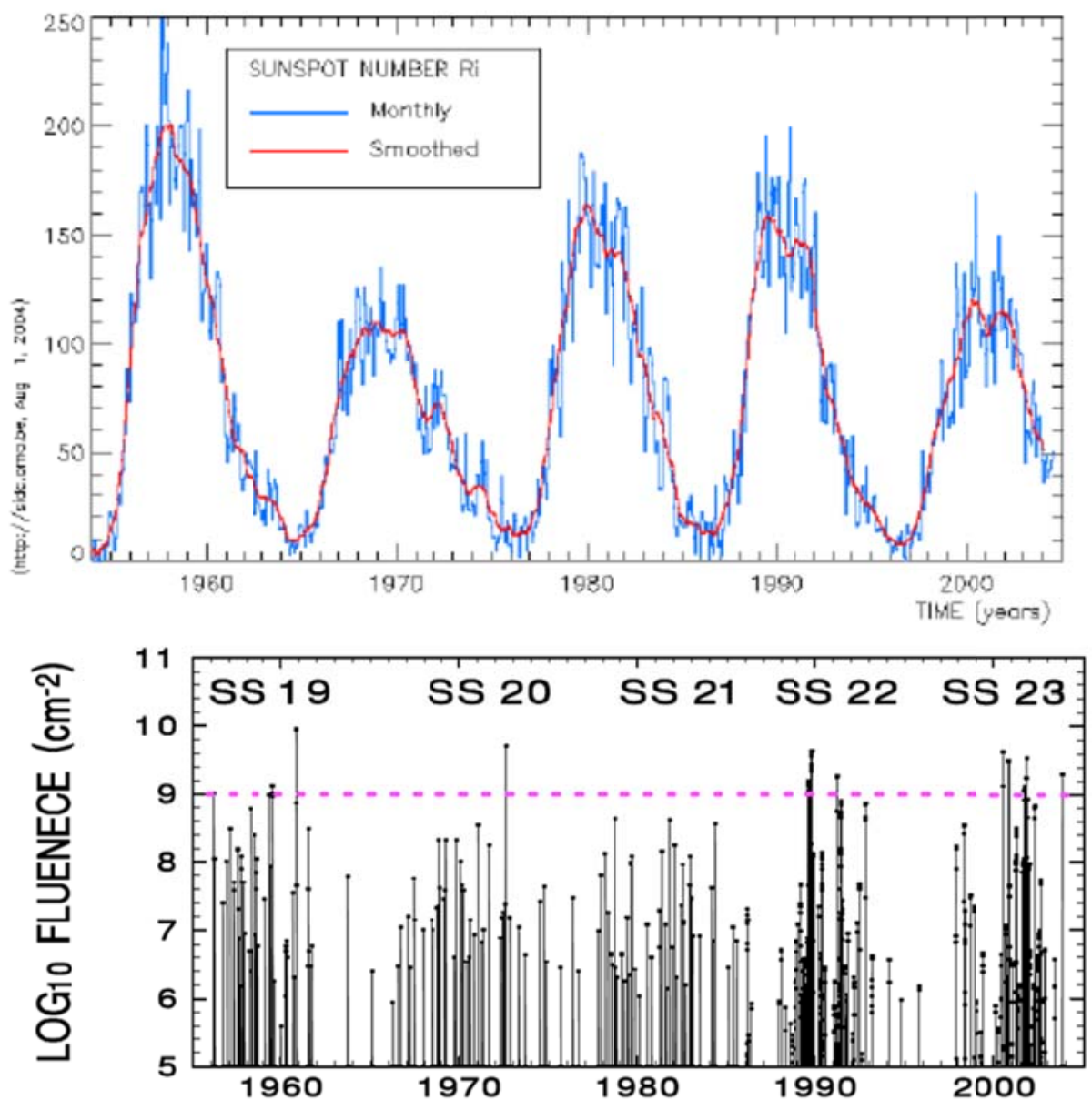

Figure 1. The sunspot number (top graph) and SPE history over several years (bottom graph), depicting the solar cycle ${ }^{9,10}$. The horizontal (magenta) dashed line in the bottom graph represents the fluence for which an event is categorized as a very large or major event.

Given that there are more sunspots visible during solar maximum, it then follows that there are more SPEs during solar maximum, and they tend to have increased intensity during this period. During solar minimum, the frequency of events is decreased and the intensity of the event is much lower than during solar maximum.

The primary concern with SPEs is that scientists are unable to predict when, and with what severity, events will occur. Fortunately, if crew remains within the spacecraft during the mission, most of the radiation from SPEs can be mitigated with passive shielding via optimized spacecraft design and material selection ${ }^{4,5}$.

\section{Galactic Cosmic Rays}

Galactic cosmic rays (GCRs) originate from outside the solar system and are very high energy particles (typically in the range of $100 \mathrm{MeV}$ to $100 \mathrm{GeV}$ ). The GCRs are composed of the nuclei of all the elements in the periodic table, with the highest abundance element being hydrogen ${ }^{6-9,11}$. For human spaceflight, the particles of most concern are the heavy GCR ions since they tend to be the most difficult to mitigate with shielding and the most damaging to humans and electronics as a result of the much higher kinetic energy and much more intense secondary particle showers compared to trapped and SPE radiation ${ }^{4,5,9}$.

The GCRs are modulated by the solar cycle, when the solar wind interacts with the GCRs, thereby reducing the energy and eliminating the lower energy particles ${ }^{12}$. During solar maximum, the GCR flux is considerably reduced. However, during solar minimum, the GCR flux increases. Thus, the GCR flux is anti-correlated with solar activity (Fig. 2) ${ }^{11-13}$. 


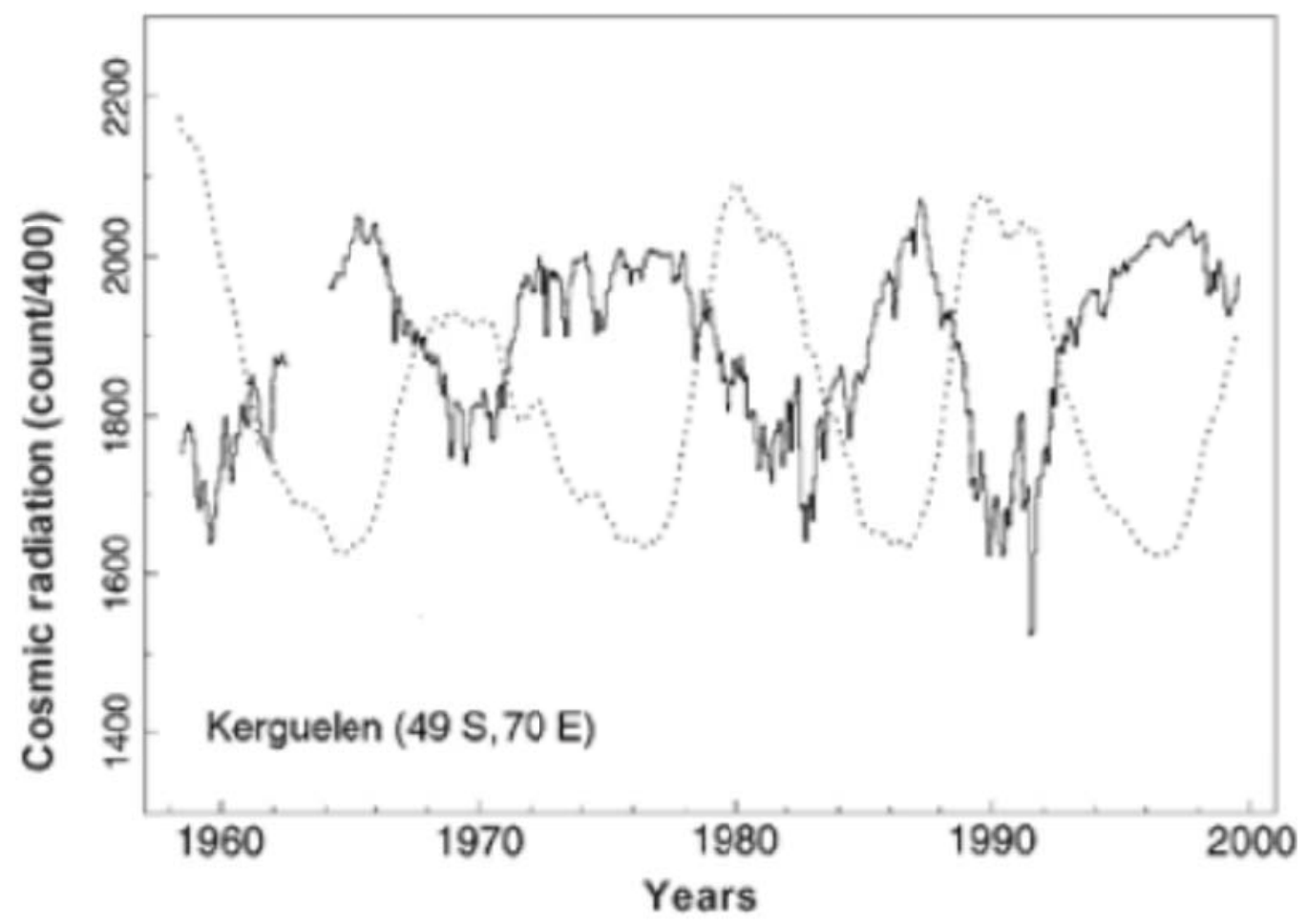

Figure 2. Plot of the solar cycle (dots) and corresponding GCR secondary particle shower neutron measurements on Earth's surface (solid line) ${ }^{9}$.

While the GCRs are modulated by the solar cycle, there is always some exposure as a result of the higher energy GCRs that are not deflected by the solar wind. Furthermore, the major challenge with GCRs is that they are too high energy and produce secondary particle showers that are too intense to effectively shield against them with nominal spacecraft structure and consumables shielding mass, as will be shown in the following section.

\section{GCR Modulation: Solar Maximum vs. Solar Minimum Effects on Human Dose}

There are several approaches to mitigating space radiation exposure during interplanetary travel which will be discussed in detail in this paper. One concept proposed is to fly the mission during solar maximum when the GCR environment is reduced. The following section will evaluate a mission scenario using two simplified spacecraft concepts to show how materials can play a part in minimizing the radiation exposure to crew at various times in the solar cycle. Then, an analysis of the predictions for the future solar cycles will be discussed and concerns for using the method of flying during particular periods in the solar cycle will be reviewed.

A simplified mission scenario depicting a three-year mission to Mars is discussed below. The assumption made in this analysis is that the spacecraft is bombarded by constant GCR radiation throughout the mission and experiences one major SPE per year. All other smaller SPEs are assumed to be sufficiently shielded against and are not included in the total dose calculations.

Two materials are evaluated as spacecraft radiation shielding materials: aluminum and water. Typical manned spacecraft are currently made of aluminum at about $30 \mathrm{~g} / \mathrm{cm}^{2}$ thickness of the spacecraft structure and interior items without additional radiation protection. Water is being used as shielding augmentation in a simulation of an inflatable spacecraft that uses high-hydrogen content, low-atomic number materials and places all consumables along the outer surface of the spacecraft habitable volume such that the crew is also shielded by the consumables. Thus, this analysis will use the typical spacecraft thickness of $30 \mathrm{~g} / \mathrm{cm}^{2}$ as a baseline and will also evaluate scenarios with significantly more shielding added to the spacecraft.

The assessments were performed using the high charge and energy transport software (HZETRN). This software is based on a one-dimensional formulation of the Boltzmann transport equation with a straight-ahead approximation ${ }^{14-17}$. HZETRN calculations and in-flight measurements agree quite well for both the Space Shuttle and the Mir orbital station (to within a few $\%)^{16,17}$. Several historical GCR environments corresponding to different solar cycle GCR modulation levels were evaluated and the October 1989 SPE was used as the large SPE. The data 
being evaluated is the dose equivalent to the blood forming organs (BFO), which are most important with respect to late effects in crew, typical of GCR exposures. The BFO dose equivalent are plotted as a function of the solar modulation parameter to better evaluate the significance of the solar cycle on the GCR environment (Fig. 3).

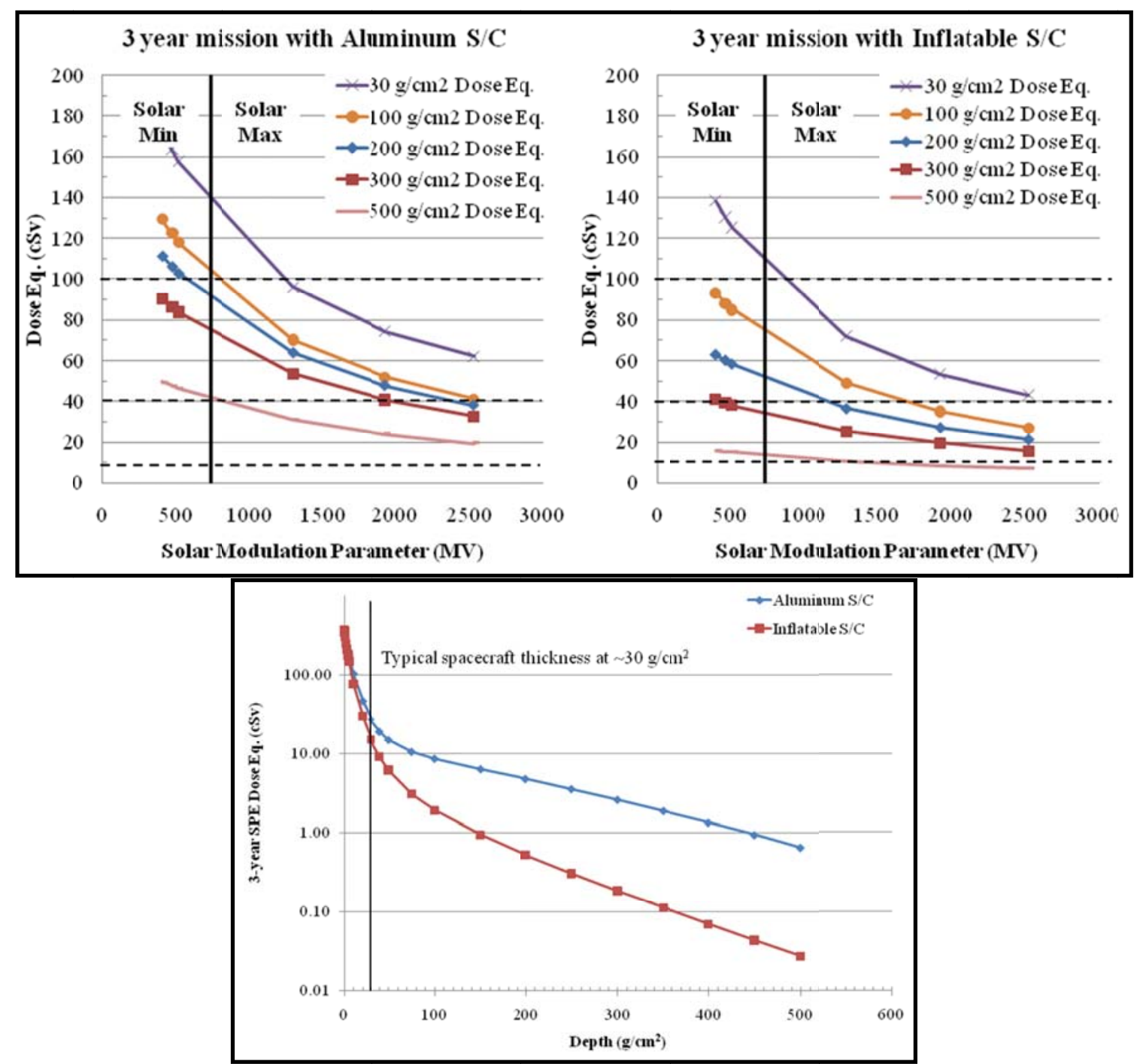

Figure 3. Mission scenario to Mars showing the BFO Dose Equivalent as a function of the solar modulation parameter (top). The top, left graph is for an aluminum spacecraft and the top, right graph is for a hybrid inflatable spacecraft using water as shielding mass. The dose equivalent is the result of three years of GCR exposure and three major SPEs. The horizontal dashed lines show potential crew dose limits. The bottom graph shows only the three-year SPE exposure for various thicknesses to demonstrate that the majority of the dose is a result of the GCR exposure and that the SPE exposure is sufficiently mitigated.

Overall, the graphs show that with increasing solar modulation parameter, the dose decreases. As the shielding mass of the spacecraft increases, the overall dose for a given solar modulation parameter also decreases. Given this information and depending on the crew dose requirements for a three-year mission, several different trades can be made. It is clear that a three-year mission using a typical spacecraft without any radiation shielding augmentation (i.e. $30 \mathrm{~g} / \mathrm{cm}^{2}$ ) is not possible if career exposure limits on the crew are between 10 and $40 \mathrm{cSv}$. However, if the crew dose limits were set at $100 \mathrm{cSv}$, a mission would be possible using an inflatable spacecraft with only an additional $70 \mathrm{~g} / \mathrm{cm}^{2}$ of shielding mass. Another trade is to consider flying the mission during solar maximum versus solar minimum. If an aluminum spacecraft with $100 \mathrm{~g} / \mathrm{cm}^{2}$ thickness were used instead, the mission could only be performed during solar maximum. 


\section{E. Predictions of Future Solar Cycles}

The mission scenario showed that performing the mission during solar maximum (or at greatest solar modulation parameter) would greatly reduce the overall dose to the crew. Therefore, it is necessary to analyze the current solar cycle and understand what will be the near-term future activity of the sun. There are many groups focused on understanding the sun and learning how to predict future activity, but at this time there are no viable prediction methods that are highly accurate $e^{18,19}$.

However, a majority of the solar physics community is predicting that the sun is entering a period of very minimal activity, similar to the Maunder minimum or the Dalton minimum ${ }^{19-21}$. The previous cycle, cycle 23 , tended to be particularly weak and there is some belief that the activity of the previous minimum gives indications of the strength of the following cycle ${ }^{19}$. Furthermore, cycle 24 has started much later than initially predicted, as shown in Fig. $4^{22}$, and is now progressing lower than the "low prediction" shown in the left graph of Fig. 4. Thus, the predictions of cycle 24 being a weak cycle seem to hold some validity.
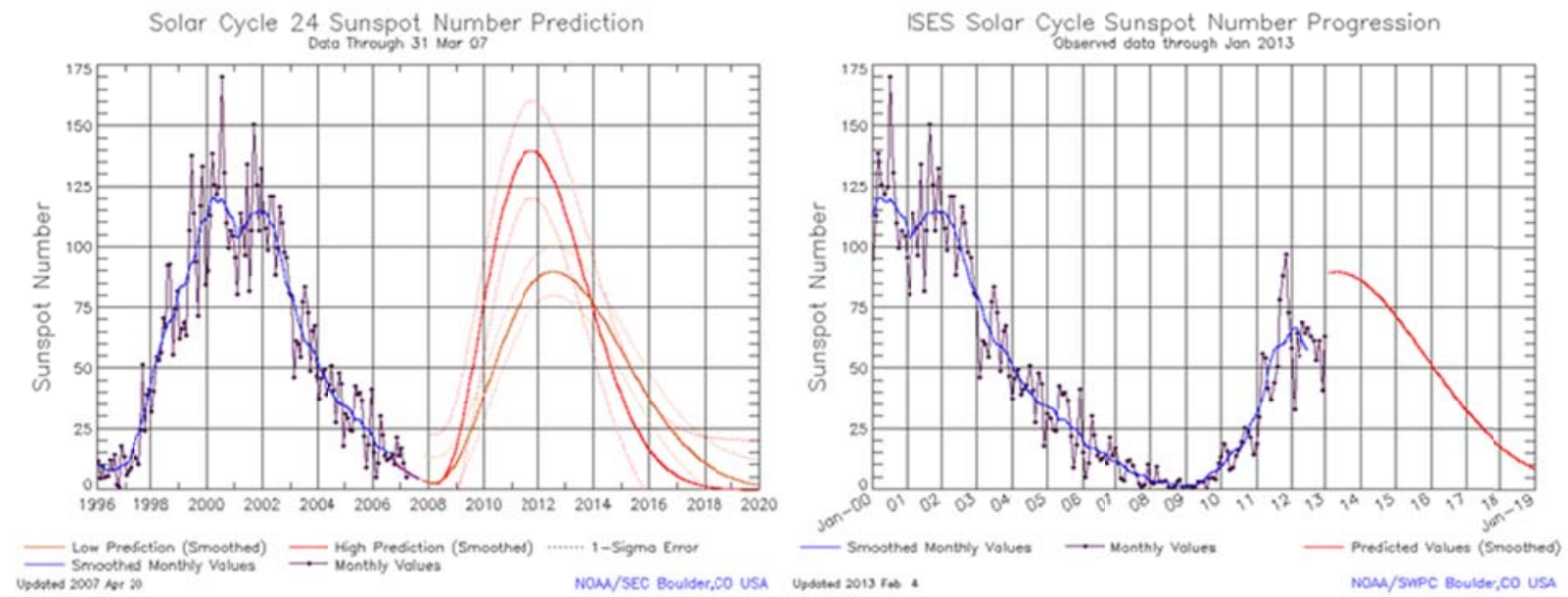

Figure 4. Cycle 24 sunspot prediction in March 2007 (left) and the most current data on Cycle 24 sunspot progression (right) ${ }^{22}$.

If the sun is entering another grand minimum period, the assumption that we may be able to fly Mars missions during solar maximum will not hold, at least not for the next 20 years. Furthermore, slowly declining solar activity beyond what we've experienced in the past fifty years infers that GCR activity will increase to levels we have not seen in the time of human space travel. An analysis of the historical GCR spectra is given by Bonino, et al. and shows that during the Maunder minimum the GCR flux more than doubled compared to the GCR flux of the past fifty years, and during the Dalton minimum, the GCR flux during solar minimum was anywhere from 1.5 to 2 times larger than current solar minimum GCR levels ${ }^{23}$. 


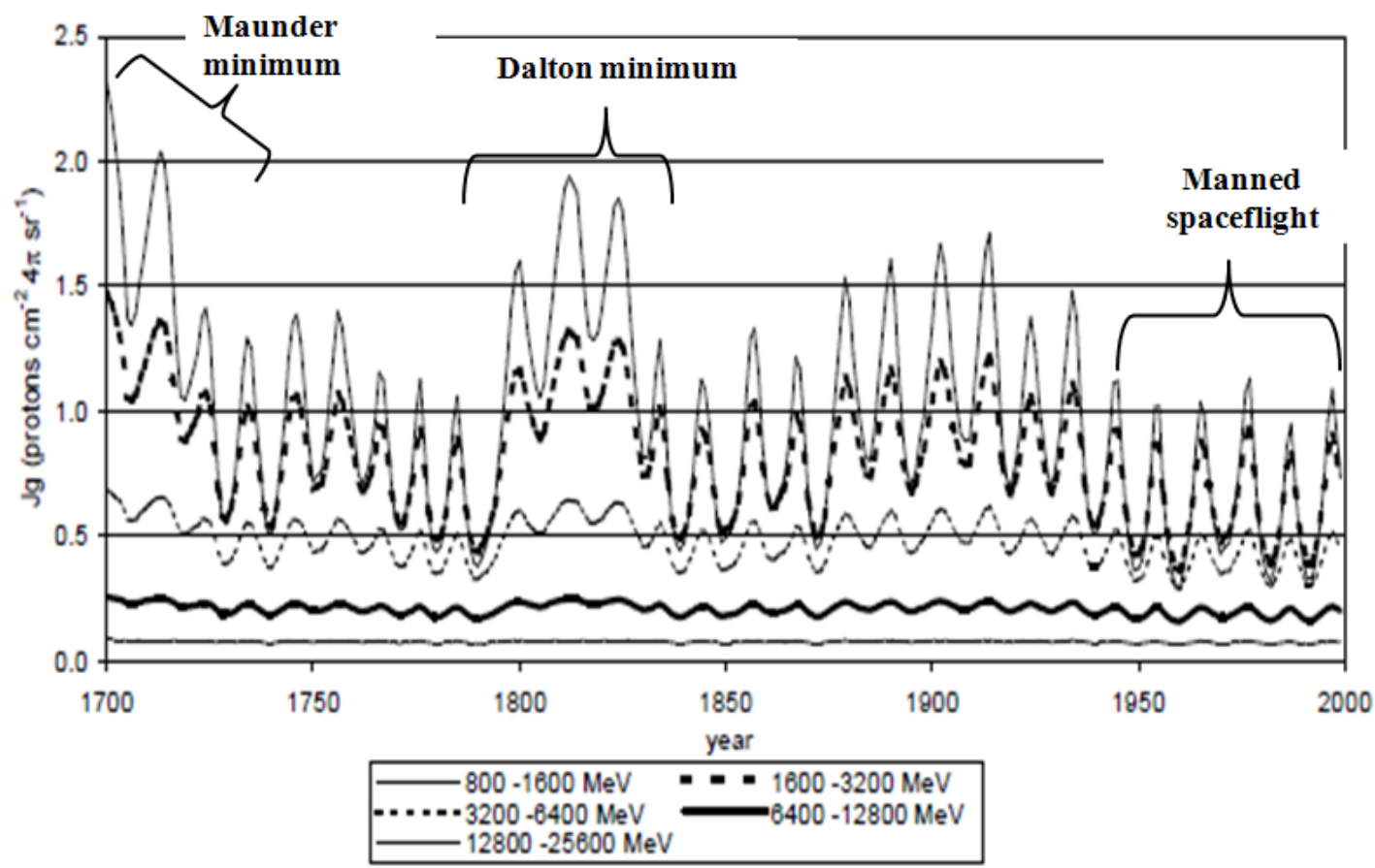

Figure 5. Proton flux of the historical GCR environment as a function of GCR proton kinetic energy ${ }^{23}$.

Additionally, if we compare the GCR flux during solar minimum of the manned spaceflight era in Fig. 5 with the data collected in Fig. 3 we see that the dose equivalent is fairly consistent per solar modulation parameter, which corresponds to the regularity of the GCR flux during solar minimum. Thus, if the predictions of the solar cycle are correct, then over the next thirty to fifty years, we will see an increase in the overall GCR flux. The flux during solar maximum will be similar to the flux we are currently experiencing at solar minimum and the flux at solar minimum will be 1.5 to 2 times higher than we've ever experienced. Consequently, we will not be able to complete a three-year Mars mission without heavily shielded spacecraft and faster traverse times (via new propulsion methods).

\section{Space Radiation Crew Dose Limits}

\section{A. Background}

Aware of the risks presented by the space radiation environment, the Gemini program (1965-1966) astronauts were the first crewmembers to wear passive radiation film badges ${ }^{24}$ that were read out post-flight. During the Apollo lunar landing program (1969-1972), crew radiation exposure guidance was governed by U.S. Atomic Energy Commission regulations (Title 10, Code of Federal Regulations, 1971) and U.S. Department of Labor Standards (Title 29, Code of Federal Regulations, 1971) ${ }^{25}$. Each Apollo crewmember wore a personal radiation dosimeter, and a Van Allen Belt Dosimeter (VABD) was mounted within the Command Module. The VABD contained two detectors: one for skin measurements and the other for depth-dose measurements.

During the Skylab program (1973-1974), each crewmember wore a personal dosimeter, and a VABD was mounted outside the Wardroom in the Orbital Work Shop (OWS) module.

For the Space Shuttle and International Space Station (ISS) programs, flight crews are assigned personal dosimeters that are read out post-flight. In addition, other radiation instruments, Tissue Equivalent Proportional Counter (TEPC), Radiation Area Monitors (RAM), and the Charged Particle Directional Spectrometer (CPDS), are placed at various locations internal and external to the spacecraft. The TEPC also flew on the Russian Mir space station for approximately 5 years ( half a solar cycle). 


\section{B. Crew Exposure}

Space flight radiation exposure standards, requirements, and guidance are documented in NASA Standard 3001, Volume 1 and 2, and include ${ }^{26,27}$.

$>$ Planned career exposure for radiation shall not exceed 3 percent risk of exposure induced death (REID) for fatal cancer.

DASA shall assure that this risk limit is not exceeded at a 95 percent confidence level using a statistical assessment of the uncertainties in the risk projection calculations to limit the cumulative effective dose (in units of Sievert) received by an astronaut throughout his or her career.

Dxploration Class Mission radiation exposure limits shall be defined by NASA based on National Council on Radiation Protection (NCRP) recommendations.

Planned radiation dose shall not exceed short-term limits as defined Appendix F.8, NASA Standard 3001, Vol. 1.

$>$ In-flight radiation exposures shall be maintained using the "as low as reasonably achievable" (ALARA) principle. The ALARA principle is a legal requirement intended to ensure astronaut safety. An important function of ALARA is to ensure that astronauts do not approach radiation limits and that such limits are not considered as "tolerance values." ALARA is especially important for space missions in view of the large uncertainties in cancer and other risk projection models. Mission programs and terrestrial occupational procedures resulting in radiation exposures to astronauts are required to find cost-effective approaches to implement ALARA.

As a result the following career crew radiation exposure limits as a function of age and gender were established and are reported here in Table 1 below. Table 1 lists examples of career effective dose (E) limits for a REID of 3\% for missions of one-year duration or less. Limits for other career or mission lengths vary and can be calculated using the appropriate life-table formalism. The numbers in Table 1 are based on absolute probabilities of a 3\% REID at the indicated age and gender. Application of the $95 \%$ confidence level leads to career limit on the order of a factor of ten smaller than those shown in Table 1.

Table 1: Career exposure by age and sex for missions of one year duration or less ${ }^{26,27}$.

\begin{tabular}{c|cccc}
\hline & \multicolumn{4}{|c}{ Age } \\
Sex & $\mathbf{2 5}$ & $\mathbf{3 5}$ & $\mathbf{4 5}$ & $\mathbf{5 5}$ \\
\hline Male & $52 \mathrm{cSv}$ & $72 \mathrm{cSv}$ & $95 \mathrm{cSv}$ & $147 \mathrm{cSv}$ \\
Female & $37 \mathrm{cSv}$ & $55 \mathrm{cSv}$ & $75 \mathrm{cSv}$ & $112 \mathrm{cSv}$ \\
\hline
\end{tabular}

These flight crew exposure limits have been recommended to NASA by the National Council on Radiation Protection and Measurements (NCRP) and have been legally adopted as NASA's supplementary standard in accordance with 29 Code of Federal Regulation (CFR) 1960.18.

\section{Approaches to Space Radiation Effects Mitigation for Long Term Human Interplanetary Flight}

\section{A. Problem Statement: Controlling Program Schedule and Costs Despite Dynamic and Uncertain Human Radiation Dose Requirements}

As described in the proceeding paragraphs, uncertainty in the relationship between space radiation dose and the $3 \%$ REID requirement ${ }^{4,5}$ drive any long-term interplanetary flight program immediately to habitat areal shielding density of hundreds of grams per square $\mathrm{cm}$ using currently available high-TRL materials and systems. Hundreds of grams per square $\mathrm{cm}$ of areal shielding density on the habitat correspond to hundreds of metric tons of net habitat mass, which ultimately drives the scale and cost of the entire spacecraft and program. However, as the uncertainty in the relationship between crew dose and \% REID is reduced and biomedical mitigations become available, crew dose limits corresponding to the $3 \%$ REID are expected to increase dramatically and reduce shielding mass needs correspondingly ${ }^{4,5}$. In parallel, advanced propulsion and active shielding technologies may become available during 
the development phase of the DSH project. The problem is to find an approach to accommodating reduced shielding mass and/or new technologies in a DSH development program without costly re-design, re-work, or the development of a costly architecture with multiple habitat designs.

\section{B. Compromises that will be required to incorporate radiation shielding on crewed, deep space vehicles: An ISS analog

\author{
"Our true genius is for compromise." - Shelby Foote, Civil War Historian
}

During the late 1980's and early 1990's the challenge of providing Micrometeoroid and Orbital Debris (MM/OD) protection to Space Station Freedom (SSF) appeared, at times, to be intractable. The specification for the low-earth orbit (LEO) MM/OD environment was in the process of being defined and the scientific community knew that whatever environment was specified would change over time as more data were collected.

Another aspect of the problem that the SSF Program struggled with was just how much MM/OD protection should be provided for the habitable modules and for other "MM/OD critical" items (hardware that if impacted by MM/OD would cause a catastrophic hazard to the Station and/or crew). The question of how to uniformly test MM/OD shielding concepts to determine their effectiveness against hypervelocity impacts had to be resolved. MM/OD particles have a wide range of densities, shapes and velocities and a standard test method across all of the hardware developers, including the International Partners (IPs), had to be found for hardware development and verification to proceed.

The proposed verification methods to determine the probability of crew loss over the life of the SFF varied widely as well. There were proposals to fire hypervelocity impactors at full-scale pressurized modules, analyses to determine the critical crack size that an aluminum module would fail from unstable crack growth and analyses of shield performance using the BUMPER analysis code based on experimentally determined ballistic limit equations.

When the SSF Program was transitioned to the International Space Station (ISS) Program, the Russians were brought on as an International Partner and the inclination of the ISS orbit was raised to 51.6 degrees, further exacerbating the MM/OD protection problem. The Orbital Debris flux became much greater and the shielding on the Russian elements of the ISS was designed to protect against meteoroids only.

Eventually, compromises were made among all of the stakeholders to solve the problem of protecting the ISS against MM/OD. This series of compromises are analogous to the type of compromises that will have to be made by the stakeholders responsible for providing radiation protection for crewed, deep space missions. A summary of the compromises is given in the following paragraphs along with how they can help guide those responsible for working through similar issues with regards to providing radiation protection for deep space, crewed vehicles.

\section{The Environment Compromise}

During the requirements definition phase of the ISS Program, SSP 30425, Space Station Program Natural Environment for Design, was updated to include the MM/OD environment for low-Earth orbit that the scientific community could achieve consensus on as of 1994. This environment model was used for developing designs of MM/OD shielding and assessing Probability of Non-Penetration (PNP) risk to ISS MM/OD critical items. The scientific community as well as the ISS engineers and Program management knew that our understanding of this environment would change over time. So even though the shield design was based on the LEO MM/OD environment as it was known in 1994, a documented ISS Program risk was tracked and a revised ISS PNP calculation was performed when an updated LEO MM/OD environment was baselined. (Currently ORDEM 2000 is used for ISS PNP assessment, with ORDEM 3.0 currently under review by the broad community.)

In order to develop radiation shielding concepts for deep space missions, the scientific community must achieve consensus on the SPE and GCR environments beyond LEO. Even though the solar max and solar min duration, intensity, and frequency of SPE events have uncertainty bands around them, a natural environment against which to evaluate vehicle configuration and shielding environments must be baselined. A process will have to be put in place by the deep space vehicle Program that incorporates assessments of the revised environments on the spacecraft shielding design.

\section{The Risk Compromise}

Perhaps the most difficult compromise that was required in solving the ISS MM/OD protection problem was determining the PNP risk that the ISS Program was willing to accept. The BUMPER analysis code had recently been developed. This code took ballistic limit equations for MM/OD shielding concepts, mapped these equations onto a mesh that could be tailored to represent a spacecraft geometry, accounted for spacecraft attitudes and shadowing, and then exposed that mesh to an MM/OD environment flux. The BUMPER analysis code or its 
recognized equivalent code was used for PNP verification, and the software was kept under strict configuration control. Using BUMPER, shielding concepts could be quickly assessed and a shielding mass vs. PNP curve could be developed for individual ISS elements or for the entire station configuration.

In addition, several catastrophic failure modes due to MM/OD impacts were assessed, including unstable crack growth in module pressure walls, time of useful consciousness based on the hole size due to an MM/OD impact, loss of attitude control or structural integrity due to module venting, and the probability of a crewmember being injured by secondary ejecta inside the impacted module. These assessments resulted in the minimum module wall thickness being increased to $3 / 16$ " in order to mitigate the risk of catastrophic rupture of a module due to unstable crack growth. It also produced a rough estimate that one of two penetrations would be catastrophic to the ISS.

Based on these data, the ISS program allocated PNP requirements based on an "equal area penetration risk" to MM/OD critical items. In other words, each square meter of the ISS would have equal shielding protection based on BUMPER analysis of the configuration. Overall, the ISS would have a 0.90 PNP over a ten-year, on-orbit duration assuming one of two penetrations were catastrophic. When the Russians were brought into the ISS Program, this criterion was changed to $0.81 \mathrm{PNP}$ over a ten-year period, since their modules would have roughly the same area as the U.S., European and Japanese elements. Also, more refined analysis of the catastrophic risk reduced the likelihood of a penetration being catastrophic to about one in four.

A similar process will have to be followed for determining the extent of radiation shielding that will be required for crewed, deep space vehicles. First, an analytical tool for evaluating radiation shielding effectiveness will have to be agreed upon by all stakeholders. Also, the ALARA (As-Low-As-Reasonable-Achievable) principle will have to be codified into a maximum radiation dosage over a period of time, a cancer risk level or some other agreed-to criteria, so that radiation shielding concepts can be traded against an allowable crew dosage. With the analytical tool and allowable dosage criteria in place, shielding estimates can be traded against risk, weight, vehicle configuration and cost considerations during the conceptual design phase.

\section{The Verification Compromise}

The question of formal verification of the ISS PNP requirements had huge cost implications. Many proposed solutions, such as firing projectiles at full-scale pressurized elements to verify unstable crack growth predictions were cost-prohibitive. Also, since MM/OD particles came in all shapes and sizes, and the hypervelocity guns were limited to about $7-\mathrm{km} / \mathrm{second}$, a consensus had to be developed on how to uniformly perform testing and how to incorporate those test results in a verifiable analysis.

The test community agreed that the representative hypervelocity test particle would be an aluminum sphere. They also agreed on extrapolation criteria to estimate the shield ballistic limit beyond the maximum velocity achievable during ground tests. A representative altitude of 215 nautical miles, a 51.6 degree orbital inclination and a solar flux value were also agreed upon for the purpose of analytical assessments of ISS PNP. A ten-year on-orbit lifetime was used to design the shielding and the ISS would be reanalyzed as the lifetime of the vehicle was increased.

For the purpose of verifying radiation shielding performance for deep space vehicles, similar compromises will have to be made when developing a verification strategy in order to meet cost and schedule constraints. The transport code used to assess shield performance must be agreed-upon by all stakeholders, as well as its limits of applicability. Radiation environments will have to be truncated to some degree in order to exclude conceivable worst-case events in order to develop shielding designs that can be pragmatically implemented. Representative vehicle configurations, solar flux values and in-space lifetimes will have to be specified up front in order for shielding design to proceed without placing an undue analytical or test verification burden on the engineering community. Test resources will be limited. So only those test activities that can be tied to verifying radiation shield performance should be included in the verification planning.

\section{The Augmentation Compromise}

The fourth compromise that had to be made in order to successfully implement MM/OD shielding on the ISS was to allow augmentation of the MM/OD shielding. In practice, this required the vehicle developers to scar certain areas of the ISS in order to permit EVA installation of additional MM/OD shielding. Since it was understood that the orbital debris environment would increase over time, that the ISS would probably be in-service longer than the ten-year, on-orbit lifetime used to design the MM/OD shielding, and that it may fly attitudes of additional modules to produce vehicle configurations that were not initially considered, the ISS Program management knew that additional shielding might have to be added once the ISS was operational.

On-orbit MM/OD shield augmentation has been installed on the ISS Russian Service Module, since this vehicle was initially designed to a 1980's LEO micro-meteoroid environment and launch vehicle lift constraints prevented 
pre-integrated shielding to be installed on the Service Module before launch. With the ISS planned to be on-orbit until at least 2020, the capacity to augment the MM/OD shielding may need to be employed on other parts of the ISS, if ongoing analyses indicated a penetration risk concern.

The augmentation compromise may be a driving factor in the configuration of a deep space vehicle that requires radiation protection. It is highly likely that any deep space vehicle will be in-use longer and be exposed to radiation environmental conditions not accounted for when the initial radiation shielding was sized. So, the capability to augment the radiation shielding during the deep space vehicle's mission should be considered an absolute necessity. This may drive vehicle configurations where excess volume is set aside to store expended consumables, such as water or trash, or the ability for the on-board crew to reconfigure equipment inside the vehicle to provide a temporary storm shelter in the event that short-term survival measures must be taken. This is a risk mitigation consideration that must be consciously addressed at an early stage of the deep space vehicle development so the capability to augment radiation shielding can be available once the vehicle is in operation.

\section{The Political Compromise}

Once the previous four hurdles had been overcome, the final hurdle of convincing the non-technical stakeholders outside of the ISS Program on the soundness of the approach to MM/OD shielding remained.

The U.S. Department of Defense tracks the known orbital debris to an acknowledged size of about 2.0 inches in diameter. This information is coordinated with NASA and if a possible "conjunction" between a tracked piece of debris and the ISS occurs, there is extensive analysis performed to determine if the ISS must perform a Debris Avoidance Maneuver (DAM) to avoid the debris. The ISS onboard crew waits in the Soyuz return vehicle until this threat has passed. (As of February, 2013, the ISS has moved 13 times to avoid orbital debris.) Sometimes these warnings come too late to plan a DAM, so the ISS crew remains in the Soyuz until the threat has passed.

The ISS micro-meteoroid shielding can protect against impacts from particles about 0.50 inches in diameter (this size varies somewhat based on impact angle and velocity). So as the figure illustrates, there is some residual penetration risk from MM/OD particles that can neither be shielded against nor tracked. This risk is quantified and accepted consciously by the ISS Program and all of its stakeholders.

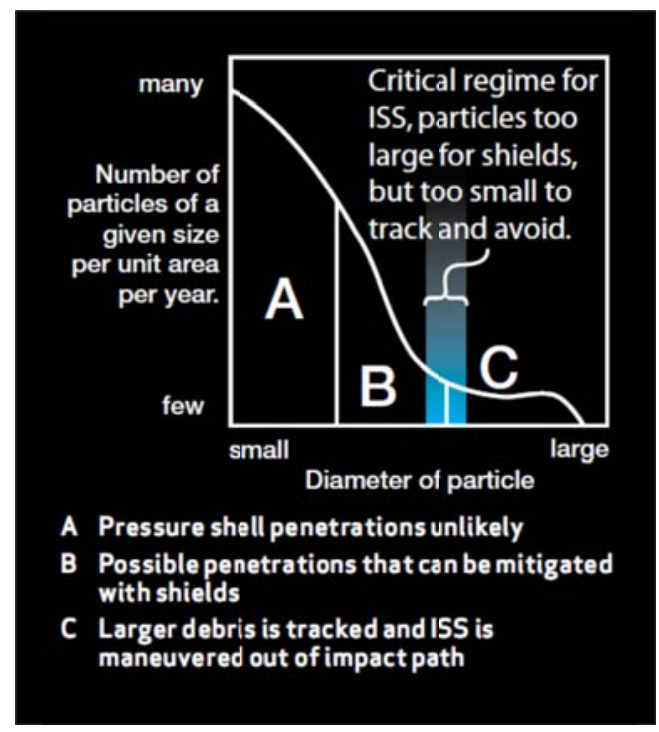

Figure 6. Depiction of the residual risk of MM/OD penetration for ISS ${ }^{28}$

Similarly, everyone involved in developing radiation protection strategies for long duration, crewed, deep space vehicles will face external stakeholders, non-advocate reviews, GAO audits, Program management and ultimately, the astronauts whose lives will be at stake, in defending the measures that have been taken to reduce the risk from both SPE and GCR to the minimum amount possible with the technology available. The four compromises that had to be made to reach an implementable engineering solution will have to be discussed over and over again in excruciating detail and must withstand the utmost scrutiny. Space radiation protection will be among the greatest challenges facing spacecraft developers as humanity moves beyond LEO. It is hoped that the lessons learned from solving the seemingly overwhelming problem of ISS MM/OD protection can guide those engaged in this endeavor towards the best solution. 
"A compass will point you true north. But it won't show you the swamps between you and there. If you don't avoid the swamps, and get bogged down, what's the use of knowing true north?” - Abraham Lincoln - Lincoln (2012)

\section{Space Radiation Human Dose Mitigation Technologies}

Total ionizing dose is simply the product of average long-term dose rate multiplied by exposure time. The definition suggests a mitigation method - simply limit exposure time. Limiting exposure time is the basic radiation dose management method used by the ISS program. ISS has no system wide requirements that drive additional shielding mass to meet crew ionizing radiation (IR) dose requirements ${ }^{29}$. In the ISS flight environment (nominally $360 \mathrm{~km}$ altitude and $51.6^{\circ}$ inclination), the baseline spacecraft structure provides more than adequate shielding to meet medical operations crew dose requirements for a six month expedition stay time. Limiting the duration of human flight operations outside the Earth's magnetosphere to times on the order of 100 to 300 days for spacecraft with typical shielding mass and materials is another example of limiting exposure time to meet IR dose requirements ${ }^{30}$.

Human flight operations to Mars or the asteroid belt would have to be completed in mission times on the order of 100 to 300 days to meet existing career IR dose limits. To our knowledge, only the high thrust/high specific impulse capabilities offered by nuclear-electric Variable Specific Impulse Magnetoplasma Rocket (VASIMR) technology could achieve the 100 to 300 day round trip flight times to Mars or the asteroid belt ${ }^{31}$. While the TRL of the VASIMR engine is relatively high $^{31}$, the flight-ready light-weight nuclear reactor needed to power the engines is not yet in development and is likely to require a long and costly development program.

Chemical, nuclear thermal, and solar electric propulsion options for human space flight to Mars and the asteroid belt all lead to IR exposure times on the order of one to four years and gross violations of the worst-case career IR dose limit for the nominal 20 to $30 \mathrm{~g} / \mathrm{cm}^{2}$ aluminum structural shielding. Long term human interplanetary flight will require IR dose control and dose effects mitigation other than limiting exposure times.

Biomedical studies aimed at better quantification of the relationship between space radiation dose and health effects, in combination with pharmaceutical IR dose effect countermeasures and enhanced post-flight health services for flight crews, are expected to dramatically reduce the need for supplemental IR shielding mass in the future, ${ }^{4,5}$. However, the development lead time for usable products is estimated to be on the order of ten years, at best, and the technical risk is high.

Active magnetic shielding approaches suffer from the same limitations as nuclear electric propulsion and biomedical mitigations, i.e. long development lead time, high technical risk and high development costs, but may eventually prove useful if long term reliable funding can be made available ${ }^{32}$.

\section{Shielding with Materials}

Spacecraft structural and consumable materials can provide a measure of space radiation human dose mitigation, and materials with improved shielding properties have been the subject of considerable development work over the past twenty years ${ }^{33}$. Point dose calculations, ground based accelerator studies and a limited number of space flight experiments have demonstrated that low-Z, high-hydrogen content materials can provide better space radiation shielding performance than structural aluminum or other higher $Z$ materials ${ }^{33}$.

However, GCR secondary particle shower effects in the human body contribute significantly to human dose, and have the effect of reducing the benefits of low-Z, high-hydrogen materials. Although the benefits of low-Z, highhydrogen materials compared to structural aluminum are still of value for the lower kinetic energy SPEs and trapped protons $s^{4,5}$.

Shielding against GCR and SPEs using low-Z, high-hydrogen content materials offers an affordable, high TRL approach to solving the space radiation crew dose problem for long term interplanetary missions. However, as can be seen by inspection of Fig. 3, areal density of shielding materials needed to provide adequate protection during the entire solar cycle is between 100 and $500 \mathrm{~g} / \mathrm{cm}^{2}$ water (depending on the crew dose limit for the mission) and it is often assumed that the total mass of the shielded DSH will be too large to be practical. As is demonstrated in the following paragraphs, the assumption that high shielding mass is necessarily impractical is shown to be potentially groundless, even in the present and future challenging NASA budgetary environment.

As an example, consider a cylindrical DSH hybrid habitat with an inflatable storage volume. The outside diameter of the hard pressure shell is four meters and the length is six meters. An inflatable pressurized storage volume is attached to the lateral surface of the cylinder and launches collapsed so the diameter of the habitat prior to inflation is less than 4.5 meters, so as to accommodate a standard Delta IV, Atlas V launch vehicle payload faring, or the somewhat larger SLS payload fairing. Once orbit is achieved, the storage volume is inflated and can be accessed by the crew through a hatch. The Hybrid habitat is shown in launch and on-orbit configuration in Fig. 10, 
Section V, below. The end domes on the hard cylinder are each equipped with a 1.4 meter diameter hatch and pressurized tunnel to permit access to other pressurized volumes in the spacecraft. The volume of the hard shell habitat is 74.4 cubic meters and the total external surface area, excluding the 1.4 meter diameter hatches on the end caps, is $97.5 \mathrm{~m}^{2}\left(9.75 \times 10^{5} \mathrm{~cm}^{2}\right)$.

The most commonly used unit of space radiation shielding thickness is the areal density expressed as $\mathrm{g} / \mathrm{cm}^{2}$. Given the area of the volume to be shielded, and a relationship between equivalent crew dose in cSv and shielding mass in $\mathrm{g} / \mathrm{cm}^{2}$, the total shielding mass needed to provide a specific equivalent dose can be easily calculated for any specific habitat configuration, radiation environment, and exposure time. The relationship between areal shielding density (water) and crew dose equivalent for a three-year flight in a worst-case, solar minimum GCR environment corresponding to a solar modulation parameter of $401 \mathrm{MV}$ combined with three October 1989 solar particle events is shown in Fig. 7. Figure 8 shows the total habit shielding mass corresponding to the dose equivalent values, and Fig. 9 shows the corresponding estimated costs for launching that mass to either LEO or a Geostationary Transfer Orbit $(\mathrm{GTO})^{34,35}$.

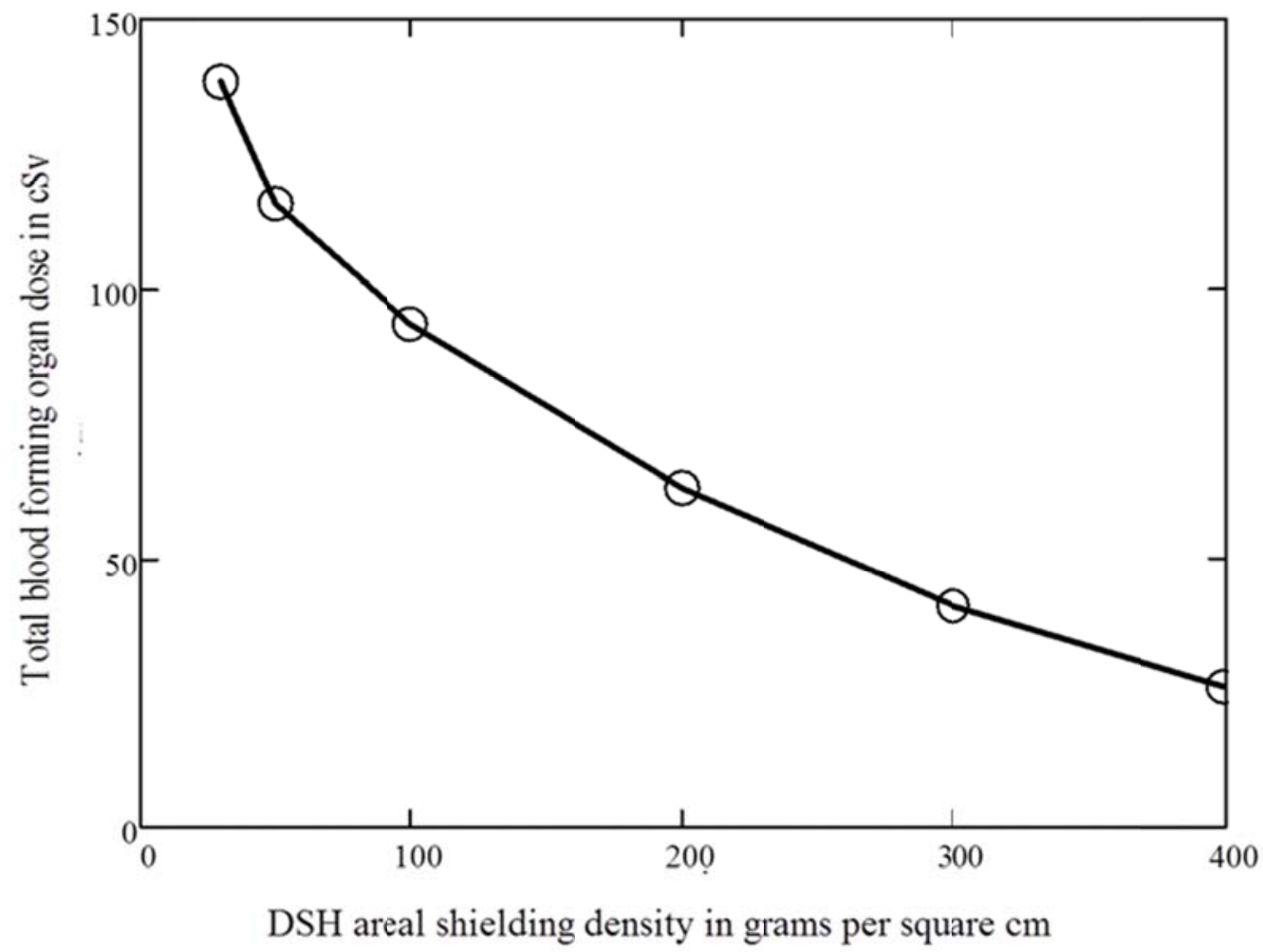

Figure 7. Total BFO dose equivalent as a function of areal density of water shielding mass for a worst-case, three-year interplanetary mission (solar minimum GCR and three October 1989 SPEs). 


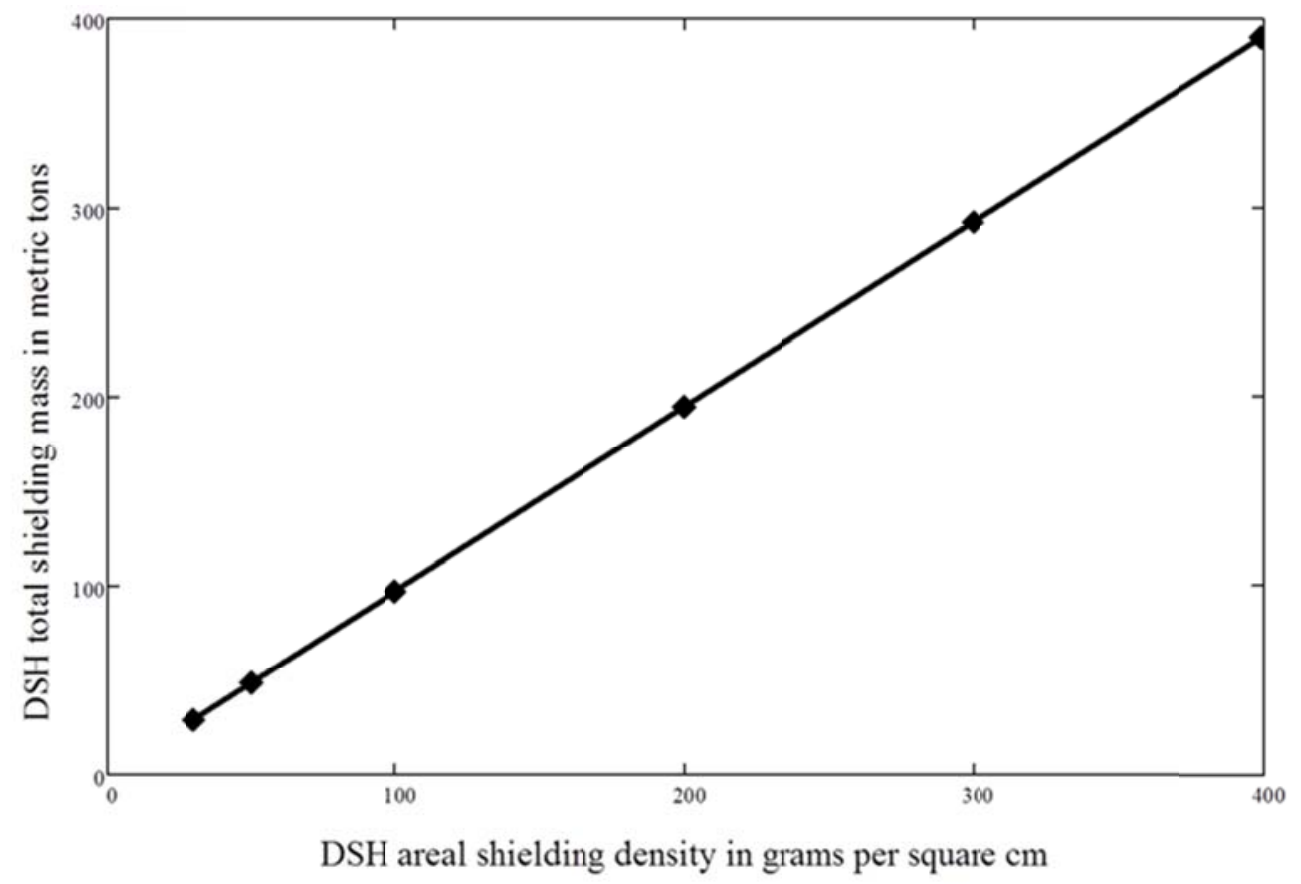

Figure 8. Total DSH shielding mass (water) corresponding to the three-year BFO dose equivalent (solar minimum GCR and three Oct. 1989 SPEs).

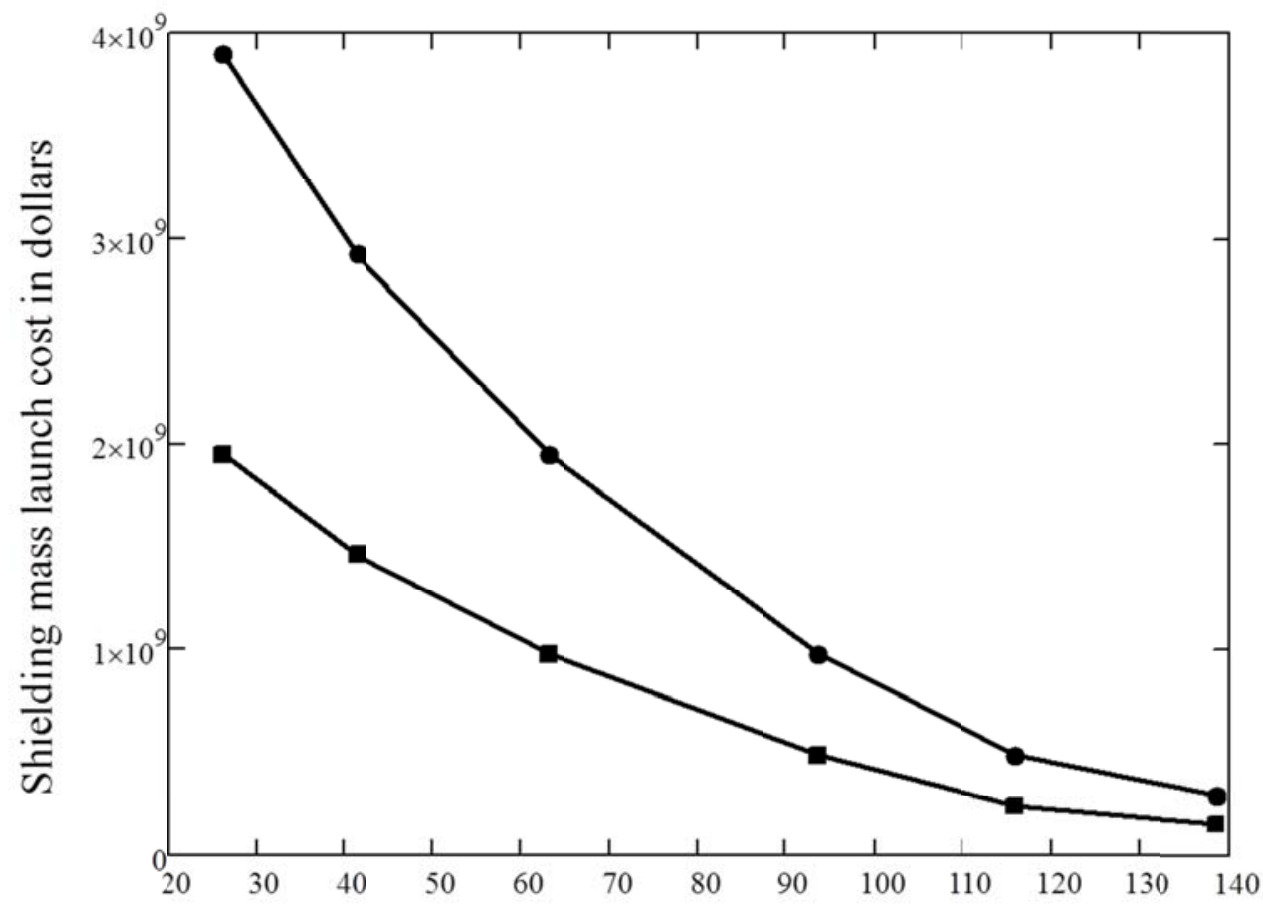

Total BFO dose for 3 year mission

Figure 9. Total DSH shielding launch costs corresponding to the three-year BFO dose equivalent (solar minimum GCR and three Oct. 1989 SPEs). Costs are plotted for direct launch to GTO (-๑-) and launch to LEO (-ח-). 
The launch cost vs. BFO dose equivalent for the three-year interplanetary flight examined here (Fig. 9) is a central consideration for implementation of the As Low As Reasonably Achievable (ALARA) approach to crew dose management, as described in NASA Standard 3001, and is driven by a cost vs. risk analysis. For example, the launch costs associated with the shielding needed to limit the three-year BFO dose equivalent to $100 \mathrm{cSv}$ is on the order of one billion dollars for direct launch to GTO and about half that for direct launch to LEO. The shielding mass needed to limit the three-year BFO dose to $20 \mathrm{cSv}$ costs on the order of two billion dollars for launch to LEO and over four billion dollars for direct launch to GTO. The high cost of direct launch to GTO compared to LEO suggests that a solar electric tug spacecraft could be profitably employed for moving large masses from LEO to GTO, but only if the subject tug can be designed, built, launched, and operated for less than about two to three billion dollars total program cost.

Another consideration in the ALARA analysis is the direct effect of large shielding masses on spacecraft and mission architecture (see Figs. 8 and 9) and cost in dollars. The rocket equation determines the payload mass fraction for a particular mission delta $\mathrm{V}$ and propulsion system specific impulse $\left(\mathrm{I}_{\mathrm{sp}}\right)$. Assuming an $11 \mathrm{~km} / \mathrm{sec}$ delta $\mathrm{V}$ requirement for a three-year Mars mission, the payload mass fractions is less that $10 \%$ for both storable $\left(\mathrm{I}_{\mathrm{sp}}=325\right.$ s) and cryogenic $\left(I_{s p}=450 \mathrm{~s}\right)$ propulsion systems ${ }^{36}$. For a solar electric system with an $I_{\text {sp }}$ of $2000 \mathrm{~s}$, the payload mass fraction is $58 \%^{36}$. A 200 metric ton habitat implies a total Earth departure mass of more than 2000 metric tons using chemical propulsion. If a high impulse solar electric system is used, the Earth departure mass can be only 344 metric tons. Low $\mathrm{I}_{\mathrm{sp}}$ chemical propulsion is not suitable if high shielding mass is needed to manage crew dose. High $I_{\text {sp }}$ electric systems enable the use of high shielding mass habitats for long term manned interplanetary exploration $^{36,37}$. Solar electric propulsion systems can support manned interplanetary exploration while more powerful and capable nuclear electric systems are being developed.

The relatively high TRL of large high-power space solar electric systems is demonstrated by the solar photovoltaic power system now flying on ISS ${ }^{37,38}$. While the interplanetary transport solar electric power system will have different specific design requirements based on different mission objectives it is that case that ISS has provided a demonstration of in-flight feasibility and validated the design and verification process for hundred kilowatt to megawatt space photovoltaic systems ${ }^{37,38}$.

The large shielding masses, and corresponding launch costs, needed to manage crew radiation dose during long term interplanetary missions is often treated as evidence that the passive shielding approach is unworkable in principle, largely on account of the cost of launching the required shielding mass. If 400 metric tons of shielding mass is needed in the worst-case, to meet a crew dose limit of $15.0 \mathrm{cSv}$ during a 3 year mission, the launch costs of the shielding mass alone (to LEO) will be on the order of 2 to 4 billion dollars, which may be considered affordable if the cost is spread-out over several fiscal years. The result is a stationary deep space habitat with a three-year stay time at one of the Earth-Moon liberation points. Inserting the same habitat into a manned interplanetary transport designed for a three-year mission drives additional launch costs for propulsion and power modules. If the shielded habitat mass is on the order of 400 metric tons, the net solar electric spacecraft mass is expected to be on the order of 690 metric tons with a total launch cost on the order of 4 to 6 billion dollars.

The nature of the ALARA process now becomes clear. For example, increasing the crew radiation dose limit to $40 \mathrm{E} \mathrm{cSv}$ from $15 \mathrm{E} \mathrm{cSv}$ can reduce net spacecraft mass to 344 metric tons from 690 metric tons leading to a launch cost saving on the order of 2 to 3 billion dollars, in addition to reducing the number of heavy lift launches needed to complete construction of the interplanetary transport.

\section{The Hybrid Inflatable Deep Space Habitat (DSH)}

One approach that lends itself to a flexible architecture is the Hybrid Inflatable module shown deployed in Fig. 10. The Hybrid Inflatable design consists of a metal or composite core surrounded by an inflatable shell. The inflatable shell consist of the standard shell layers described during the TransHab design ${ }^{39}$, an inner liner, single or multiple bladders, a structural restraint layer, micrometeoroid protective layers, and passive thermal protective layers. Racks (stowage, Environmental Control and Life Support Systems (ECLSS), avionics, dining, etc.) and internal storage are shown inside the central core. Crew quarters and a water-wall are shown on one end of the module. During Solar Particle Events (SPEs), the crew would retreat into the crew quarters surrounded by the water wall. Outside the module, attached to the outside of the central core, is an inflatable volume containing consumables and waste which doubles as additional radiation protection (shown as grey blocks in Fig. 10). 

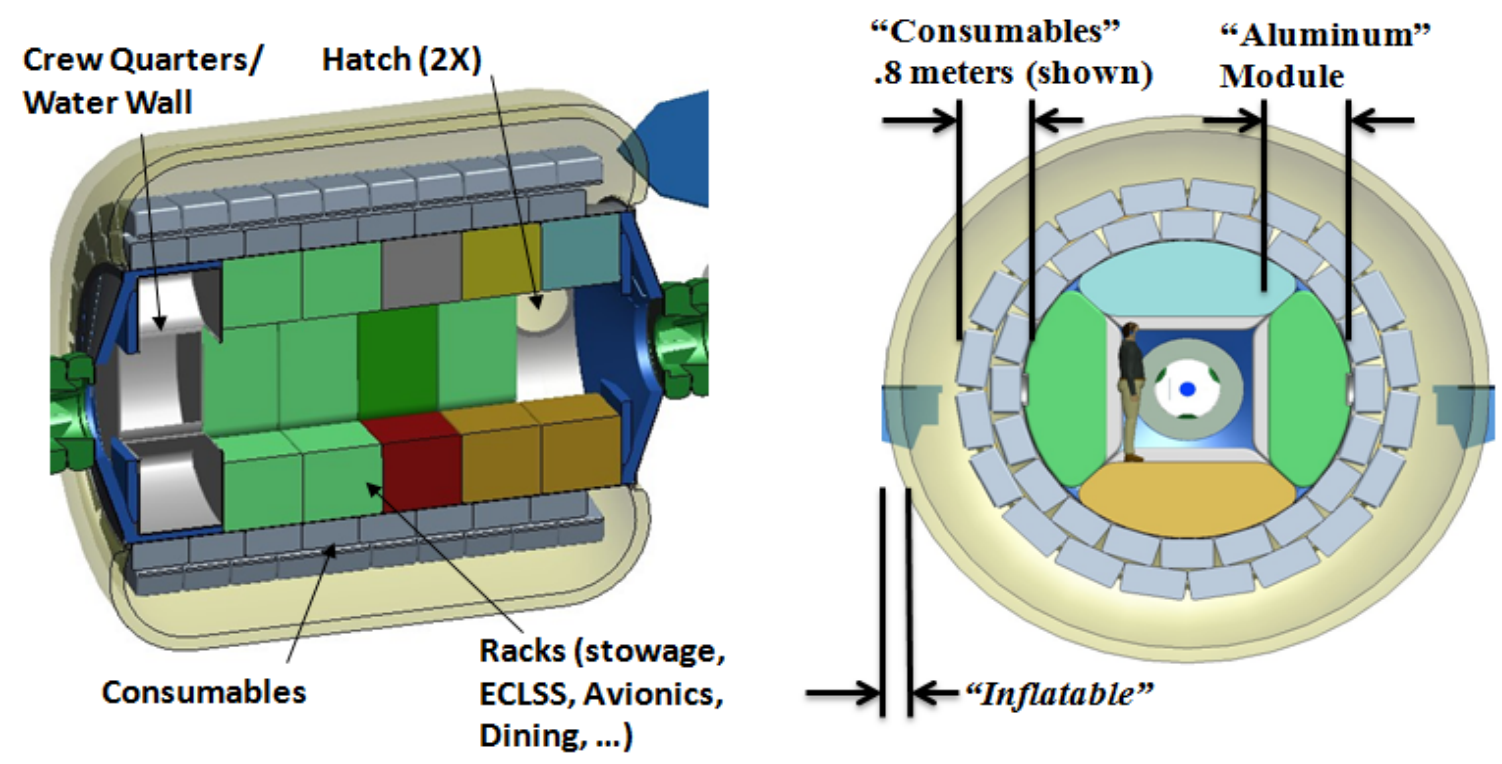

Figure 10. Hybrid inflatable design (on-orbit configuration).

Consumables are launched inside the central core and deployed to the inflatable outer shell on orbit. Additional consumables and generated waste (radiation protection) can be added throughout and on supplemental missions. The flight crews will ingress/egress between the central core and the inflatable through either of two hatches. In this configuration, the central core has a total pressurized volume of $94 \mathrm{~m}^{3}$ broken up into approximately $34 \mathrm{~m}^{3}$ of free space, $22.5 \mathrm{~m}^{3}$ of subsystem volume, $22.5 \mathrm{~m}^{3}$ of stowage volume, and $10 \mathrm{~m}^{3}$ for crew quarters. The inflatable portion provides an additional $180 \mathrm{~m}^{3}$ of pressurized volume consisting of approximately $112 \mathrm{~m}^{3}$ of free space and $68 \mathrm{~m}^{3}$ of stowage volume. Additional stowage volume can be added at the cost of crew access.

The Hybrid Inflatable Module is launched in the folded configuration with the racks and consumables/radiation protection layers prepositioned inside the central core (see Fig. 11). The module can be launched by an Expendable Launch Vehicle (ELV) and is shown packaged in a Delta IV shroud. NASA Docking Systems (NDS) are located on the forward and aft ends of the module. For this study, a propulsion bus was included to slow the module down post-insertion and support Service Module mating. Once inflated and deployed, the module will have to be attached to a service module that will provide power, propulsion, and Guidance, Navigation and Control (GN\&C), as required.

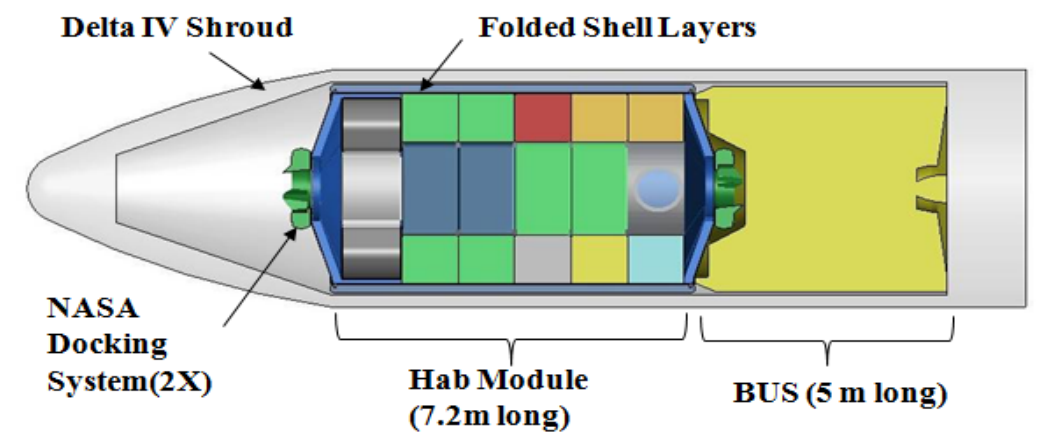

Figure 11. Hybrid Inflatable Module in Delta IV launch configuration.

As shown in Fig. 12, this architecture supports a one-year DSH mission, meeting a $40 \mathrm{cSv}$ per year guideline. For

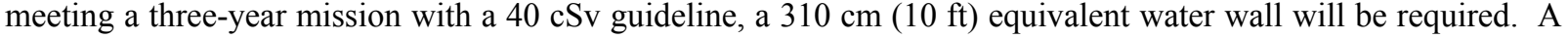
conceptual design of a Hybrid Inflatable Module, including supplemental inflatable water bags to meet the threeyear mission guideline, is shown in Fig. 13. The external inflatable water bags would require their own passive thermal and micrometeoroid protective layers, as well as compartmentalization, so that water or air could be 
added or removed incrementally during the mission build-up to address possibly changing crew dose requirements.

\begin{tabular}{|c|c|c|c|c|c|c|c|c|}
\hline $\begin{array}{c}\text { Mission } \\
\text { duration } \\
\text { in Years }\end{array}$ & $\begin{array}{c}15 \mathrm{cSV} \\
(\mathrm{cm})\end{array}$ & $\begin{array}{c}15 \mathrm{cSv} \\
(\mathrm{ft})\end{array}$ & $\begin{array}{c}40 \mathrm{cSV} \\
(\mathrm{cm})\end{array}$ & $\begin{array}{c}40 \mathrm{cSV} \\
(\mathrm{ft})\end{array}$ & $\begin{array}{c}50 \mathrm{cSv} \\
(\mathrm{cm})\end{array}$ & $\begin{array}{c}50 \mathrm{cSV} \\
(\mathrm{ft})\end{array}$ & $\begin{array}{c}100 \mathrm{cSV} \\
(\mathrm{cm})\end{array}$ & $\begin{array}{c}100 \mathrm{cSV} \\
(\mathrm{ft})\end{array}$ \\
\hline 1 & 290 & 9.4 & 50 & 1.6 & $<30$ & $<1$ & $<30$ & $<1$ \\
\hline 2 & $>400$ & $>13$ & 220 & 6.9 & 160 & 5.2 & $<30$ & $<1$ \\
\hline 3 & $>400$ & $>13$ & 310 & 10 & 260 & 8.5 & 85 & 2.8 \\
\hline 4 & $>400$ & $>13$ & $>400$ & 12 & 325 & 10 & 160 & 5.2 \\
\hline
\end{tabular}

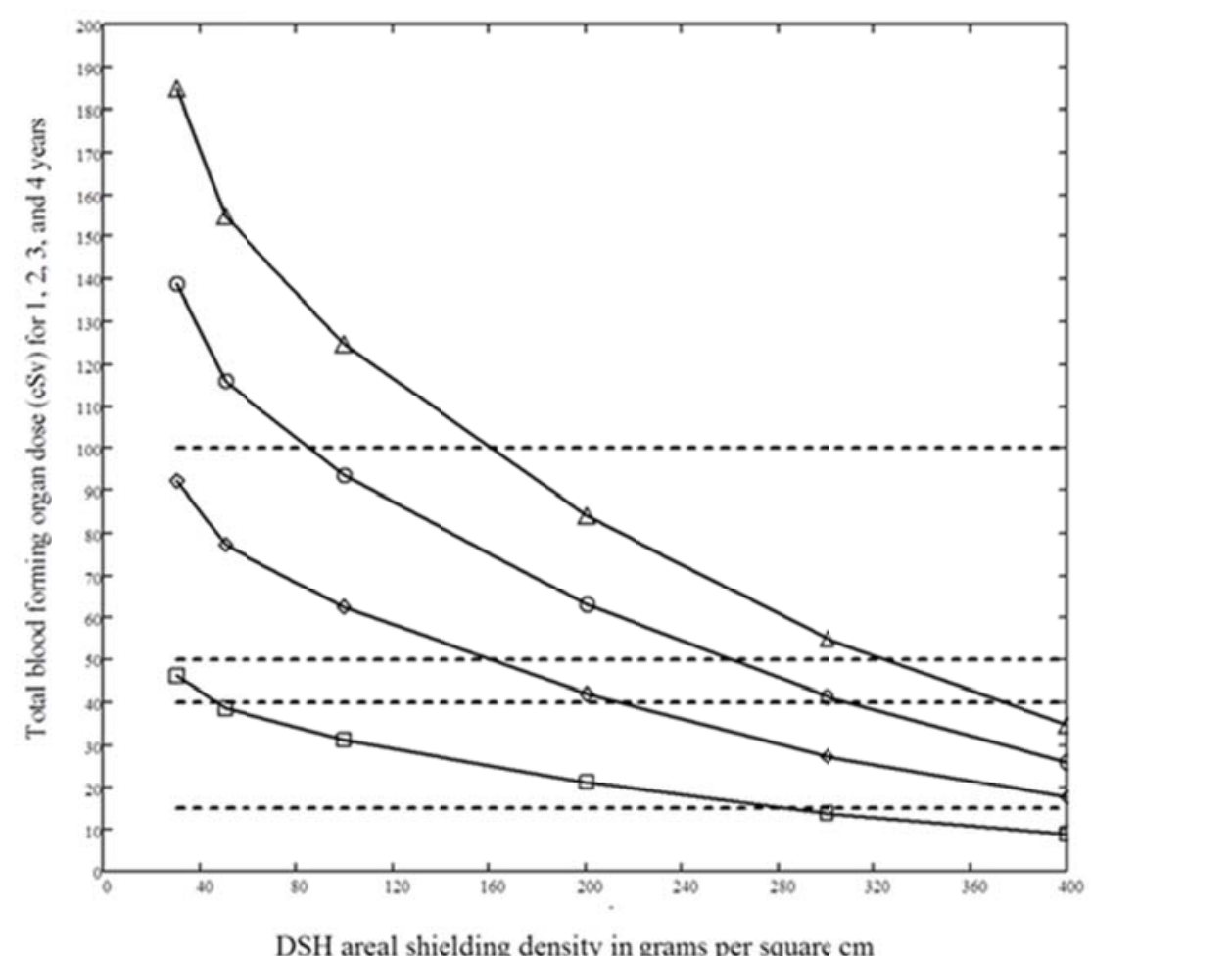

Figure 12. A graphical spacecraft shielding estimator for mission durations of one (- $\square-)$, two (- $\left.\diamond_{-}\right)$, three (-०-), and four (- - -) years. The dashed horizontal lines represent various possible crew dose limits (in cSv): $15,40,50$, and 100 . To estimate the shielding thickness (water) needed for a particular mission time and crew dose limit combination, select a dose limit and draw a horizontal line at that point. The areal density (thickness) for a particular mission duration is the $X$ coordinate corresponding the intersection point of the dose line and the areal density for that mission duration. Some examples are shown in the table above the graph. 


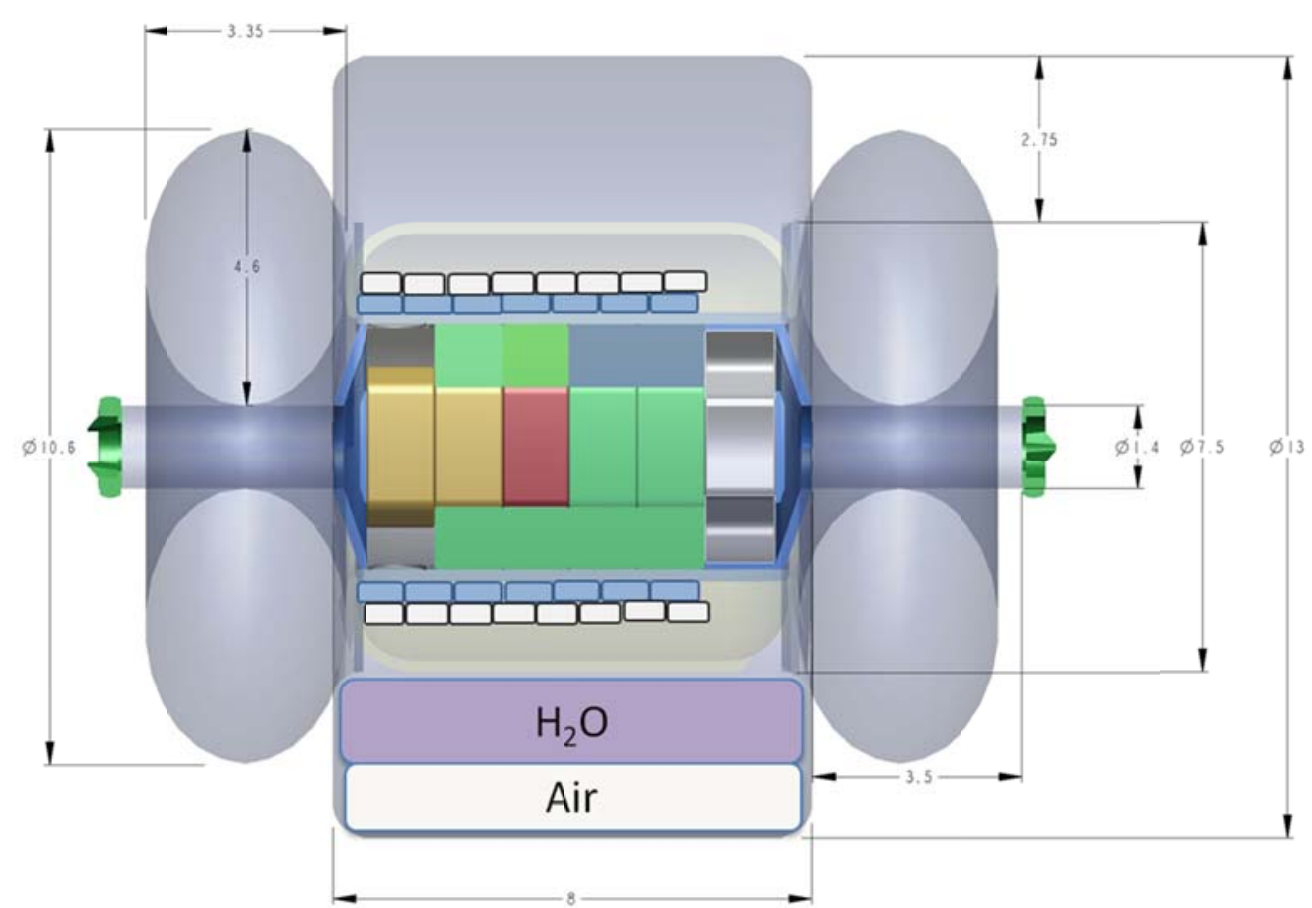

Figure 13. Hybrid Inflatable Module with additional inflatable water bags required to meet a three-year mission and a $400 \mathrm{cSv}$ guideline.

\section{How the Hybrid Inflatable DSH Enables Affordable Multi-mission Architectures}

Given the character of the current and projected NASA budget for the foreseeable future, affordability and cost control are necessarily high priority objectives for any new manned space flight initiative. At the same time, controlling the space radiation dose to the flight crew to meet career exposure limits during the mission is one of NASA's highest priorities. However, current space radiation dose limits are based on worst case analysis ${ }^{4,5}$ and are expected to increase in future as biomedical research progresses. As a result, the engineering community is faced with the challenge of designing an interplanetary transport without a stable crew radiation dose limit for design and verification purposes.

The Hybrid Inflatable DSH offers a simple solution to the changing dose requirements problem. A single DSH design can accommodate a wide range of crew dose requirements by simply changing the water shielding mass in the inflatable external shielding mass containers. In this way one core habitat design can meet the needs of a variety of missions and mission dose requirements without costly redesign or re-work.

The inflatable pressurized volume outside the hard shell core provides shielding using consumables as waste, though the 22 metric tons of stores needed for a three-year mission cannot provide enough shielding to meet current career dose limits defined in NASA Standard 3001. The relatively simple, external water tanks can be used to augment the basic core habitat shielding as needed for specific missions, and the mass of water can be reduced when crew dose limits are increased or flight opportunities at solar maximum appear unexpectedly.

It should be noted that a single DSH design that the agency can use for a variety of manned interplanetary flights over many years reduces or eliminates the costs associated with multiple mission-specific designs or periodic mission-specific re-design and rework. The Hybrid Inflatable DSH can also readily accommodate new technology as progress is made in nuclear electric propulsions, active shielding, and biomedical research.

\section{Summary and Conclusions}

The Hybrid Inflatable DSH combined with electric propulsion and high power solar-electric power systems offer a near TRL-now solution to the space radiation crew dose problem that is an inevitable aspect of long term manned interplanetary flight. Spreading program development and launch costs over several years can lead to a spending plan that fits with NASA's current and future budgetary limitations, enabling early manned interplanetary operations with space radiation dose control, in the near future while biomedical research, nuclear electric propulsion and active shielding research and development proceed in parallel. Furthermore, future work should encompass laboratory validation of HZETRN calculations, as previous laboratory investigations have not considered 
large shielding thicknesses and the calculations presented at these thicknesses are currently performed via extrapolation.

\section{Acknowledgments}

Special thanks to Jasen Raboin (NASA-JSC/ES2) who developed the original idea of utilizing an hybrid inflatable structure to support a flexible architecture capable of providing additional radiation protection using consumables, waste, and dedicated masses.

\section{References}

${ }^{1}$ National Research Council, Technical Evaluation of the NASA model for Cancer Risk to Astronauts Due to Space Radiation, The National Academies Press, Washington, D.C., 2012.

${ }^{2}$ Townsend, L. W., Badhwar, G. D., Braby, L. A., Blakely, E. A., Cucinotta, F. A., Curtis, S. B., et. al., Report No. 153 - Information Needed to Make Radiation Protection Recommendations for Space Missions Beyond LowEarth Orbit, National Council on Radiation Protection and Measurements, Bethesda, 2006.

${ }^{3}$ Office of the Administrator, "NASA Strategic Space Technology Investment Plan," NASA Headquarters, Washington D.C., 2012.

${ }^{4}$ Durante, M., Cucinotta, F. A., "Physical Basis of Radiation Protection in Space Travel", Reviews of Modern Physics, Vol. 83, 2011, pp. 1245-1281.

${ }^{5}$ Cucinottaa, F. A., Kim, M-H.Y., Ren, L., "Evaluating Shielding Effectiveness for Reducing Space Radiation Cancer Risks," Radiation Measurements, Vol. 41, 2006, pp. 1173 - 1185.

${ }^{6}$ Hastings, D., Garrett, H., Spacecraft Environment Interactions, Cambridge University Press, Cambridge, New York, 1996, pp 208-244. 2000.

${ }^{7}$ Friedlander, M. W., A Thin Cosmic Rain: Particles from Outer Space, Harvard University Press, Cambridge,

${ }^{8}$ Longair, M. S., High Energy Astrophysics Volume 1: Particles Photons and their Detection,_Cambridge University Press, Cambridge, 1992

9NASA, "Human Integration Design Handbook,” NASA SP-2010-3407, 2010.

${ }^{10}$ Smart, D. F., Shea, M. A., Dreschhoff, G. A. M., Spence, H. E., Kepko, L., "The Frequency Distribution of Solar Proton Events: 5 Solar Cycles and 45 Solar Cycles," Solar and Space Physics and the Vision for Space Exploration Conference, NASA-GSFC, 2005.

${ }^{11}$ Usoskin, I. G., Solanki, S. K., Schussler, M., Mursula, K., Kovaltsov, G. A., “A Physical Reconstruction of Cosmic Ray Intensity since 1610," Journal of Geophysical Research, Vol. 107, No. A11, pp. SSH 13-1 - SSH 13-6, 2002.

${ }^{12}$ Wiedenbeck, M.E., David, A. J., Leske, R. A., Binns, W. R., Cohen, C. M. S., Cummings, A. C., et. al., "The Level of Solar Modulation of Galactic Cosmic Rays from 1997 to 2005 as Derived from ACE Measurements of Elemental Energy Spectra," 29th International Cosmic Ray Conference, Vol. 00, Pune, 2005, pp. 101-104. 21.

${ }^{13}$ Beringer, J., et al. (Particle Data Group), “Cosmic Rays,” Physical Review, Vol. D86, No.010001, 2012, pp. 1-

${ }^{14}$ Wilson, J. W., Badavi, F. F., Cucinotta, F. A., Shinn, J.L., Badhwar, G. D., Silberberg, R., et al., "HZETRN: Description of a Free-Space Ion and Nucleon Transport and Shielding Computer Program," NASA Technical Paper 3495, 1995. 
${ }^{15}$ Slaba, T. C., Blattnig, S. R., Badavi, F. F., "Faster and More Accurate Transport Procedures for HZETRN," Journal of Computational Physics, Vol. 229, No. 24, 2010, pp. 9397-417.

${ }^{16}$ Badhwar, G. D., Konradi, A., Braby, L. A., Atwell, W., and Cucinotta, F. A., "Measurements of Trapped Protons and Cosmic Rays from Recent Shuttle Flights," Advances in Space Research, Vol. 14, 1994, pp. 67-72.

${ }^{17}$ Badhwar, G. D., Konradi, A., Atwell, W., Golightly, M. J., Cucinotta, F. A., Wilson, J. W., et. al., "Measurements of LET Spectra on the MIR Orbital Station and Comparison with Radiation Transport Models," Radiation Measurements, Vol. 26, 1996, pp. 147-158.

${ }^{18}$ Pesnell, W. D., “Solar Cycle Predictions (Invited Review),” Solar Physics, Vol. 281, No. 1, 2012, pp. 507-532.

${ }^{19}$ Choudhuri, A., Chatterjee, P., Jiang, J., "Predicting Solar Cycle 24 with a Solar Dynamo Model,“ Physical Review Letters, Lett. 98, No. 131103, 2007.

${ }^{20}$ Duhau, S., de Jager, C., "The Forthcoming Grand Minimum of Solar Activity," Journal of Cosmology. Vol. 8, 2010, pp. 1983-99.

${ }^{21}$ Uzal, L. C., Piacentini, R. D., Verdes, P. F., "Predictions of the Maximum Amplitude, Time of Occurrence, and Total Length of Solar Cycle 24," Solar Physics, Vol. 279, No. 2, 2012, pp. 551-60.

${ }^{22}$ NOAA, "Solar Cycle Progression Web Page," Space Weather Prediction Center [online database], URL: http://www.swpc.noaa.gov/SolarCycle/index.html [cited 6 Februry 2013].

${ }^{23}$ Bonino, G., Cini Castagnoli, G., Cane, D., Taricco, C., Bhandari, N., "Solar Modulation of the Galactic Cosmic Ray Spectra since the Maunder Minimum," Proceedings of ICRC, 2001, pp. 3769-72.

${ }^{24}$ Richmond, R. G. “Radiation Dosimetry for the Gemini Program,” NASA TN D-6695, 1972.

${ }^{25}$ Bailey, J. V., "Chapter 3: Radiation Protection and Instrumentation," SPE-368 Biomedical Results of Apollo [online database], URL: http://history.nasa.gov/SP-368/s2ch3.htm [cited 6 February 2013].

${ }^{26}$ NASA, "NASA Space Flight Human System Standard - Volume 1: Crew Health,” NASA-STD-3001, Vol. 1, 2009.

${ }^{27}$ NASA, "NASA Space Flight Human System Standard Volume 2: Human Factors, Habitability, and Environmental Health,” NASA-STD-3001, Vol. 2, 2011.

${ }^{28}$ NASA, "Micrometeoroid and Orbital Debris (MMOD) Protection," International Space Station (ISS) Interactive Reference Guide [online], URL: http://www.nasa.gov/externalflash/ISSRG/pdfs/mmod.pdf [cited 6 February 2013].

${ }^{29}$ Lengyel, D. M., "International Space Station (ISS) Program/Radiation Exposure/Effects on Crew," Public Lessons Learned [online database], URL: http://www.nasa.gov/offices/oce/llis/1057.html [cited 2 May 2013].

${ }^{30}$ Cucinotta, F. A., Kim, M. H. Y., Chappell, L. J., "Space Radiation Cancer Risk Projections and Uncertainties," NASA TP 2013-217375, 2013.

${ }^{31}$ Chang Díaz, F. R., Carter, M. D., Glover, T. W., Ilin, A. V., Olsen, C. S., Squire, J. P., et. al., "Fast and Robust Human Missions to Mars with Advanced Nuclear Electric Power and VASIMR Propulsion," Proceedings of Nuclear and Emerging Technologies for Space 2013, Albuquerque, 2013.

${ }^{32}$ Westover, S. C., Meinke, R. B., Battiston, R., Burger, W. J., Van Sciver, S., Washburn, S., et al., "MAARSS: Magnet Architectures and Active Radiation Shielding Study,” NASA Final Report, 2012.

21

American Institute of Aeronautics and Astronautics 
${ }^{33}$ Wilson, J. W., Cucinotta, F. A., Miller, J., Shinn, J. L., Thibeault, S. A., Singleterry, R. C., et. al., “Approaches and Issues Related to Shield Material Design to Protect Astronauts from Space Radiation," Materials and Design, Vol. 22, 2001, pp. 541-554.

${ }^{34}$ Futron Corporation, "Space Transportation Costs: Trends in Price per Pound to Orbit 1990-2000," 2002, [online], URL: http://www.futron.com/upload/wysiwyg/Resources/Whitepapers/

Space Transportation_Costs_Trends_0902.pdf, [cited 6 February 2013].

${ }^{35}$ Space Exploration Technologies Corp., "Falcon Heavy Overview," Falcon Heavy [online database], URL: http://www.spacex.com/falcon_heavy.php, [cited 6 February 2013].

${ }^{36}$ Strange, N., Landau, D., Brophy, J., Merrill, R. G., Dankanich, J., "This Way to Deep Space: Electric Propulsion Human Missions to the Moon, Asteroids, and Mars," Future In-Space Operations (FISO) Colloquium, California Institute of Technology, 2012.

${ }^{37}$ Hoffman, D. J., Kerslake, T. W., Hojnicki, J. S., Manzella, D. H., Falck, R. D., Cikanek III, H. A., et al, "Concept Design of High Power Solar Electric Propulsion Vehicles for Human Exploration," NASA TM - 2011217281, 2011.

${ }^{38}$ Brophy, J. R., Gershmann, R. G., Strange, N., Landau, D., Merrill, R. G., Kerslake, T., "300 kW Solar Electric Propulsion System Configuration for Human Exploration of Near-Earth Asteroids," Proceedings of the 47th AIAA/ASME/SAE/ASEE Joint Propulsion Conference, San Diego, 2011.

${ }^{39}$ De la Fuente, H., Raboin, J., Spexarth G., Valle, G., “TransHab: NASA's Large-Scale Inflatable,” Proceedings of the 2000 AIAA Spacecraft, Structures, Structural Dynamics, and Materials Conference, Atlanta, 2000. 